\title{
Performance Evaluation of Circular Flange Bolted Connection in Ultra High Performance Fiber Reinforced Concrete Segmented Communication Tower
}

\author{
Doaa Talib Hashim¹, Farzad Hejazi ${ }^{1 *}$, Mohd Saleh Jaafar ${ }^{1}$, Voo Yen Lai² \\ 1 Department of Civil Engineering, Faculty of Engineering, University Putra Malaysia, \\ Serdang, 43400 Seri Kembangan, Selangor, Malaysia, \\ 2 Dura Technology Sdn BhD, 31200 Chemor, Perak, Malaysia \\ *Corresponding author, e-mail: farzad@fhejazi.com
}

Received: 15 June 2018, Accepted: 05 August 2019, Published online: 30 September 2019

\begin{abstract}
This study herein presents investigations about behavior of circular flange bolted connection (CFBC) in ultra high performance fiber reinforced concrete (UHPFRC) hollow segmented communication tower subjected to lateral dynamic load. The CFBC consists of two flanged concrete, cast together with the structural segment tubes and then connected using steel bolts. The paper is illustrated with CFBC joint of 500mm flange thicknesses, and 8M25 high strength steel bolts coming from a typical real design tower. For this purpose, the full scale CFBC joints for communication tower are made from Ultra High Performance Fiber Reinforced Concrete (UHPFRC). The connection was cast and experimentally tested by applying cyclic lateral load using dynamic actuator. The lateral strength and stiffness resistance of the UHPFRC CFB connections were evaluated in this study. Besides, a rigorous FEM analysis was executed in order to evaluate the performance of CFBC in the communication tower by investigating the mechanism of force transfer, load bearing capacity as well as failure behavior of the circular flange bolted connection (CFBC) under lateral cycling loading. The experimental and numerical analysis results showed the ability of UHPFRC circular bolted connection to resist the applied lateral loads. In addition, the considered model revealed that for joints under tension, bolts were seriously not subjected to bending moments which is due to the prying effect. This was made possible by the provision of adequate flange thickness and strength of the UHPFRC material.
\end{abstract}

\section{Keywords}

communication tower, ultra high performance fiber reinforced concrete, circular flange bolted connection, precast hollow tower, lateral shear capacity

\section{Introduction}

The application of bolted connections in many areas of engineering design has been popular for several years. In civil engineering, bolted connections are often used in beam to column connections for steel structures. Lately, extensive research has been conducted on the behavior of these joints taking into cognizance of both dynamic and static states [1-4]. The resistance, stiffness and ductility of each component of the joint can be calculated and combined to joint resistance [5].

Joints with bolts are usually employed in the form of flange connections for various shapes. In particular, Circular flange-bolted connections (CFBC) are utilized in aircraft engines as well as pressure pipe systems and aircraft engines [6], while in civil engineering structures, they are generally employed in several types of tubular structures.
Circular tubes are extensively applied in several structures, such as telecommunication towers, guyed masts and windmills. Typically, these structures have very large dimensions which ought to be partitioned into sections due to assembly constraints. Each segment is pre-fabricated individually and then connected together by applying the CFBC on site. Since the joints are the main component that transfers the vertical and lateral loads therefore, a lot of attention is concentrated on the mechanical behavior of CFBC and its effect on the entire structure [7]. Cao and Bell [8] have discussed on the prying effect arising from these kinds of joints. Also, Schaumann and Seidel [9] and Schaumann and Kleineidam [10] have demonstrated the FE modelling and failure analysis of CFBC. The carrying capacity has been approximated on the account 
of linear distribution of loading about the flange taking the attainment of ultimate capacity at specific section as defining failure to be significantly less when the flange is fully modelled owing to redistribution. Lately, Pavlovic et al. [11] suggested a new design for joints assembly which is applied to a single overlapping friction connection with long opened slotted hole. Abidelah et al. [12] reported the flexural rigidity of bolts and its effects on the behavior of steel joints. Based on engineering design philosophy, tubular connections are generally assumed to be rigid or pinned. However, Gutkowski [13] described that such an assumption could lead to considerable errors in structural response. Furthermore, recent examinations of bolted circular joints revealed their complexity and non-linearity arising from friction, contact forces as well as bolt pre-stressing. Study in this regard over the past two decades dealt with numerous important challenges such as connection rigidity and its effect on the dynamic behavior of the overall structure. These investigations comprise of design models, numerical studies and experimental approaches. Swiercz et al. [14] employed Virtual Distortion Method to describe bolted joint characteristics in frame structures.

Furthermore, Blachowski et al. [15] presented a system localizing damage in frame structures with one loosened bolted connections. The connection is composed of two steel flanges, welded to the structural tubes, and then connected together with pre-tensioned bolts. Also, Bogacz et al. [16] studied bolt connections in rail engineering. Stocki et al. [17] deliberated on the reliability challenges of spot weld joints for structural use in the automotive industry while the behavior of bolted flange connections under loadings of both cyclic and monotonic nature is also explained by Van-Long et al. [18]. These connections were subjected to axial tensional forces applied monotonically for low-and high cycle fatigue test. These tests permit the definition of the behavior of connections for this loading type. Schwingshackl et al. [6] observed that flange model is strongly dependent on steady stress/load distribution across these joint and on non-linear elements. In addition, Luan et al. [19] also observed via mechanical examinations that them exist differences between the axial stiffness of the bolted flange joint while in compression and tension. Moreover, Heinisuo et al. [1] applied the component system for the structural modelling in three dimensions of steel joints. Results of the investigations were evaluated in terms of both local and global analysis. The proposed system was verified in the beam-to-column joints using detailed 3D non-linear finite element analysis. Validation of results was executed with experimental results on the end-plate splice joints of rectangular tubular structures. Couchaux et al. [20] debated the global behavior of CFBCs which were subjected to complex loads of axial forces and bending moments taking into cognizance of both elastic and elasto-plastic conditions of the flange material. Also, the application of the technique of reduce order modelling in damage detection was proposed by Yang et al. [21]. Results from numerical analysis in this study were buttressed with exciting experiments executed on a shaking table of a 1:3 scale six-storey steel framed structure. Damages at joints were simulated by releasing the connection bolts. An alternative method for damage location in structural connections was also proposed by Pnevmatikos [22]. In this study, plastic hinges within the framed structure under earthquakes excitation were detected via the application of discrete wavelet transform. He et al. [23] proposed global vibration method in which comparison of damaged and undamaged models were highlighted. This was achieved via a lightening mast comprising two pipes and connected together with a bolted flange connection. The introduction of logistic function transformation enabled an unconstrained problem to be achieved which allowed the localization of the damage and its magnitude thus confirming the theoretical assumptions were in a good agreement with results from experiments. Experimental studies on flanged joint of tubular members were examined by Perttola and Heinisuo [24]. This work studied the joint which was subjected to different relative positions of the bending moment and bolts after which the experimental data were then compared with mechanical 3D model. Moreover, Hanson and Hornish [25]. Evaluated practical formulae for design of bolted joints in launch vehicles. Comparisons were made between the results obtained from the formulae proposed which were based on idealized models and the numerical results generated using FEM. It was inferred that flange model could provide non-linear behavior of joints under external forces and changes in temperature. Patrakkos and Tizani [26] examined the behavior of a relatively new type of anchored blind-bolt connection for concrete-filled hollow profiles. The recorded experimental results revealed the forms of the damaged connection via pull-out test. An et al. [27] researched on a method based on degree of dispersion in order to study the damage and loss of stiffness in a laboratory full scale beam with flexible connections. In all of the above mentioned works, both theoretical 
and experimental results demonstrated that the mechanical properties of joints are crucial issues in the design of structures. Typical among them are CFBCs, which plays a significant role in the behavior of the whole structure both in dynamic and static conditions.

Observing the cross- sectional counter stresses of the prestressed connection of Blachowski and Gutkowski [7], it is noted that flanges were in contact along the outer borders. In the same vein, due to deformation on the flanges the inner borders became separated, a phenomenon described as prying effect. Several researchers have reported this effect among which include is Cao and Bell [8]. The same Blachowski and Gutkowski [7] and Cao and Bell [8] reported this prying effect in their study in which the relationship between the forces on the bolt and tensional force applied to the connection were examined. The differences exist only in numbers that resulting from the relationships flange diameters to their thickness.

Deformations on the flanges could occur without prying because they depend upon the flange thickness and the bolt pre-tensioning. The prying effect fades away as the flanges and post-tensioning becomes thicker and smaller respectively. The flange deformation results in bolt rotation of same heads in opposite manner Fig. 1 and this causes bolt bending. This is an important issue which should be considered in CFBC design together with axial stresses as varying stresses in bolts during tower movement could cause fatigue collapse. The presence of prying effect in the ring flange connection causes a non-linear increase in bolt forces with an increment in applied load which eventually leads to gap opening in tension zone [11].

According to the reviewed literature, the bolted connection capacity in structures has been reported for steel and concrete-filled steel towers. However, scarce information on the performance of UHPFRC circular flange bolted connection (CFBC) which is a key factor in the response
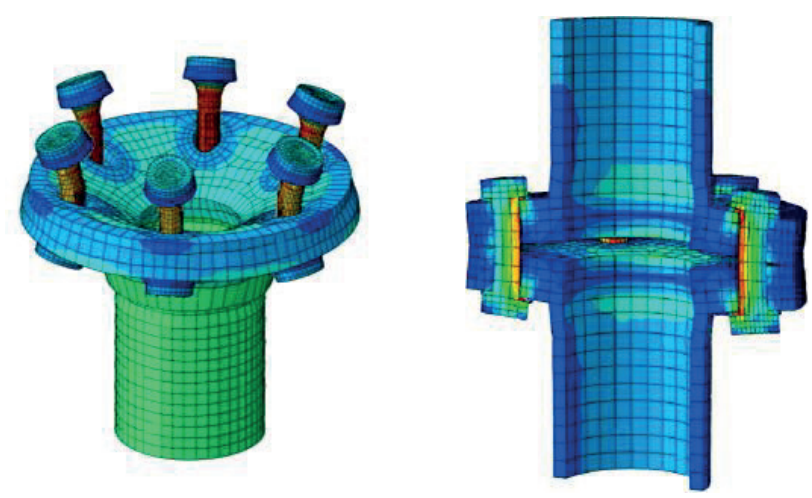

Fig. 1 Bending of bolts under tension of connection by Blachowski [7]

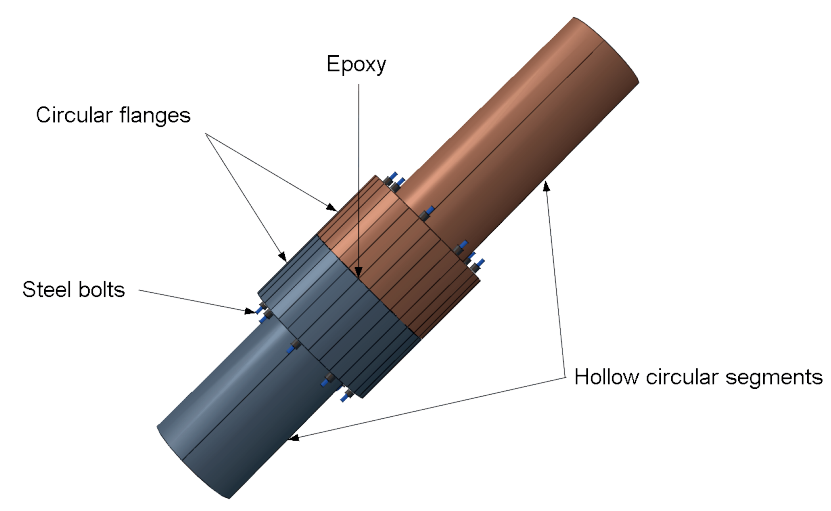

Fig. 2 UHPFRC circular flange bolted connection

of concrete or UHPFRC hollow tower subjected to lateral loads was observed. Therefore, in the current study, the CFBC joint in UHPFRC transmission tower of $30 \mathrm{~m}$ height was considered and the performance of the precast CFBC with epoxy resin subjected to lateral cyclic loads was evaluated. For this purpose, the experimental test was conducted on a full-scaled specimen hollow tower segments and CFBC by applying lateral cyclic load at the top of the upper segment. Also, finite element analysis was employed to evaluate the shear behavior of the connection as well asthe bending behavior in the hollow segment subjected similar loadings as well.

\section{CFBC joint for UHPFRC communication tower}

In this study, CFBC joint for transmission tower of 30 $\mathrm{m}$ height was designed and constructed using UHPFRC material in Ipoh/Malaysia. The CFBC consists of two circular hollow flanges with sections of hollow tower segments connected to each other using steel bolts and epoxy resin, as shown in Fig. 2. The communication tower under consideration was segmented into three sections, with each segment $10 \mathrm{~m}$ high. Each segment was made from ultra high performance fiber reinforced concrete as shown in Fig. 3. The tower was connected to the foundation base of dimension $4 \times 4 \times 1$ meters as length, width, and height respectively. The foundation was fixed to the ground using nine number of $300 \times 300 \mathrm{~mm}$ reinforced concrete embedded piles. The tower was pre-stressed with $8 \mathrm{~S} 15$ strand cables of $230 \mathrm{kN}$ pre-stressed force in each segment in addition to $8 \mathrm{~T} 16$ steel reinforcement at both edges of each segment as shown in Fig. 4. The UHPFRC material was considered as the construction material for the communication tower due to its indubitable properties. CFBC in UHPFRC structure is termed as an interconnecting set of elements between the tower's sections. 


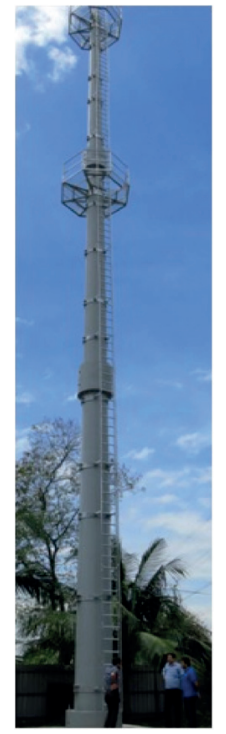

(a)

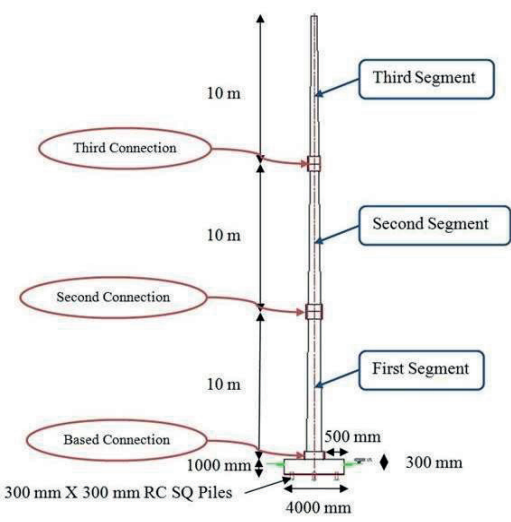

(b)
Fig. 3 The whole communication tower

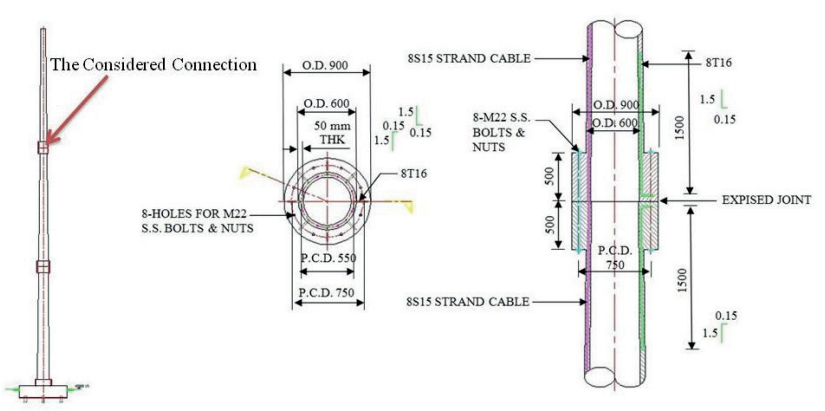

Fig. 4 The CFBC connection details

In order to evaluate the behavior of the circular flange bolted connection (CFBC) in the UHPFRC tower, the top CFBC connection at the second and the third segments of the $30 \mathrm{~m}$ UHPFRC tower as shown in Fig. 4 was considered in this study. The failure mechanism of the CFBC and segments and the transfer of the forces and moments through the connection were investigated experimentally using cyclic test with dynamic actuator and validated using numerical analysis.

\section{Wind design load}

To evaluate the capacity of the UHPFRC connections against the lateral forces and the moment distribution, Euro code 3, Section 3.1 [28] and Section 3.2 [29] were used to calculate the designed shear forces and designed moments in the connection and the tower segments. Malaysian standard [30] was used to calculate the designed wind load for the UHPFRC tower. The details of the tower under consideration in terms of height, weight and volume are given in Table 1.
Table 1 Details of the considered tower

\begin{tabular}{lccc}
\hline Section & $\begin{array}{c}\text { Height } \\
(\mathrm{m})\end{array}$ & $\begin{array}{c}\text { Weight } \\
(\text { ton })\end{array}$ & $\begin{array}{c}\text { Volume } \\
\left(\mathrm{m}^{3}\right)\end{array}$ \\
\hline UHPFRC communication tower & 30 & 16 & 6.62 \\
First segment & 10 & 7.42 & 3.09 \\
Second segment & 10 & 5.32 & 2.18 \\
Third segment & 10 & 3.24 & 1.35 \\
\hline
\end{tabular}

Table 2 Static calculations of the ultimate and serviceability limit states

\begin{tabular}{|c|c|c|c|c|}
\hline & \multicolumn{2}{|c|}{$\begin{array}{c}\text { Ultimate And } \\
\text { Serviceability Limit States }\end{array}$} & \multicolumn{2}{|c|}{ Serviceability Limit State } \\
\hline & $\begin{array}{c}\text { Design } \\
\text { Shear Force } \\
(\mathrm{kN}), \\
\mathrm{V}_{\mathrm{Ed}, \mathrm{w}}\end{array}$ & $\begin{array}{l}\text { Design } \\
\text { Moment } \\
(\mathrm{kNm}), \\
\mathrm{M}_{\mathrm{Ed}, \mathrm{w}}\end{array}$ & $\begin{array}{c}\text { Design } \\
\text { Shear Force } \\
(\mathrm{kN}), \\
\mathrm{V}_{\mathrm{Ed}, \mathrm{w}}\end{array}$ & $\begin{array}{l}\text { Design } \\
\text { Moment } \\
(\mathrm{kNm}), \\
\mathrm{E}_{\mathrm{d}, \mathrm{w}}\end{array}$ \\
\hline $\begin{array}{l}\text { Joint } 2 \\
(\mathrm{~h}=20 \mathrm{~m})\end{array}$ & 13.1 & 61 & 9.35 & 44 \\
\hline $\begin{array}{l}\text { Joint } 1 \\
(\mathrm{~h}=10 \mathrm{~m})\end{array}$ & 30.5 & 275 & 21.8 & 197 \\
\hline $\begin{array}{l}\text { Base Joint } \\
(\mathrm{h}=0)\end{array}$ & 50.8 & 676 & 36.3 & 483 \\
\hline
\end{tabular}

Table 3 Seismic load calculations of the ultimate limit state.

\begin{tabular}{|c|c|c|c|c|}
\hline & \multicolumn{2}{|c|}{$\begin{array}{c}\text { Ultimate And } \\
\text { Serviceability Limit States }\end{array}$} & \multicolumn{2}{|c|}{ Serviceability Limit State } \\
\hline & $\begin{array}{c}\text { Design } \\
\text { Shear Force } \\
(\mathrm{kN}), \\
\mathrm{V}_{\text {Ed,eq }}\end{array}$ & $\begin{array}{l}\text { Design } \\
\text { Moment } \\
(\mathrm{kNm}), \\
\mathrm{M}_{\mathrm{Ed}, \mathrm{eq}}\end{array}$ & $\begin{array}{c}\text { Design } \\
\text { Shear Force } \\
(\mathrm{kN}), \\
\mathrm{V}_{\text {Ed,eq }}\end{array}$ & $\begin{array}{c}\text { Design } \\
\text { Moment } \\
(\mathrm{kNm}), \\
\mathrm{E}_{\mathrm{d}, \mathrm{eq}}\end{array}$ \\
\hline $\begin{array}{l}\text { Joint } 2 \\
(\mathrm{~h}=20 \mathrm{~m})\end{array}$ & 12.5 & 58 & 8.89 & 42 \\
\hline $\begin{array}{l}\text { Joint } 1 \\
(\mathrm{~h}=10 \mathrm{~m})\end{array}$ & 28.2 & 317 & 20.1 & 226 \\
\hline $\begin{array}{l}\text { Base Joint } \\
(\mathrm{h}=0)\end{array}$ & 29.4 & 864 & 21 & 617 \\
\hline
\end{tabular}

According to the static calculations for both the ultimate and serviceability limit states, the maximum design shear and maximum design overturning moment in the tower's connections due to wind load are illustrated in Table 2.

\subsection{Calculation of seismic load}

The designed seismic load was calculated using International Building Code IBC [31]. The design shear forces and overturning moments in the tower's connection for both the ultimate and serviceability limit states are given in Table 3. Besides, the distribution of the design shear forces and overturning moments on the tower is illustrated in Fig. 5 and Fig. 6 for the ultimate limit state and serviceability limit state, respectively. 

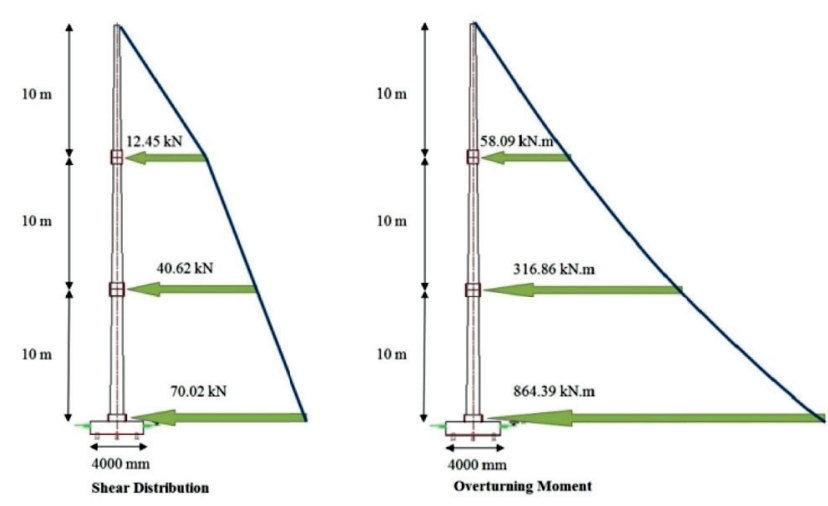

Fig. 5 Shear and moment distribution in the ultimate limit state
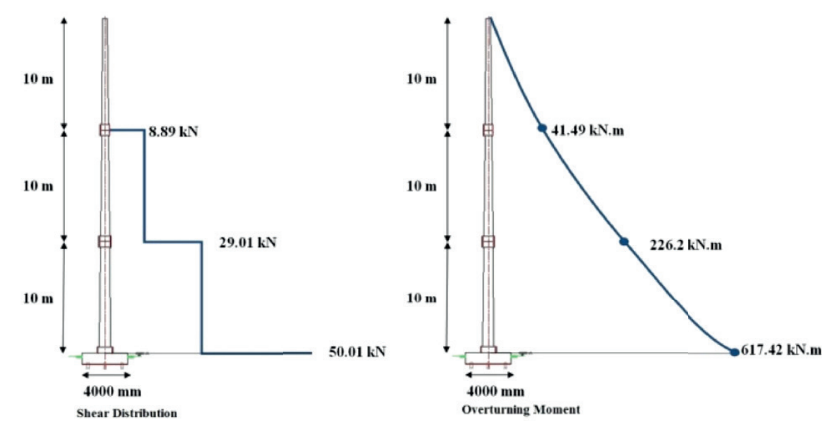

Fig. 6 Shear and moment distribution in the serviceabilty limit state

\section{Evaluation of the CFBC capacity in the segmented tower under cyclic load}

The top CFBC joint of the communication tower was considered in this studyto evaluate the maximum moment in the CFBC and the tower segment due to the applied lateral load. Also, the shear capacity in both connection and tower body are evaluated. The CFBC designed for the experimental test include two circular flanges, top and the bottom section of the second and third hollow segment tower, respectively as shown in Fig. 7 segment of the hollow tower with $2.5 \mathrm{~m}$ height and flange thickness of $0.5 \mathrm{~m}$ was cut from the top of the second hollow segment. Beside, a hollow tower segment with $1.5 \mathrm{~m}$ height and flange thickness of $0.5 \mathrm{~m}$ was cut from the bottom of the third hollow segment Fig. 8. Then, the two hollow tower segments were connected to each other using 8M25 bolts in their flanges. In addition, an epoxy material was used between the two surfaces of the flanges to improve the connection capacity.

In order to tie the specimen to the strong floor during the experimental test, the hollow segment (that has been cut from the second segment) has been grouted in UHPFRC foundation from its bottom as shown in Fig. 9. The UHPFRC foundation has been designed with $1.8 \mathrm{~m}$ width, $2 \mathrm{~m}$ length, $1 \mathrm{~m}$ height and has been tied to the strong floor by using 6M60 bolts.

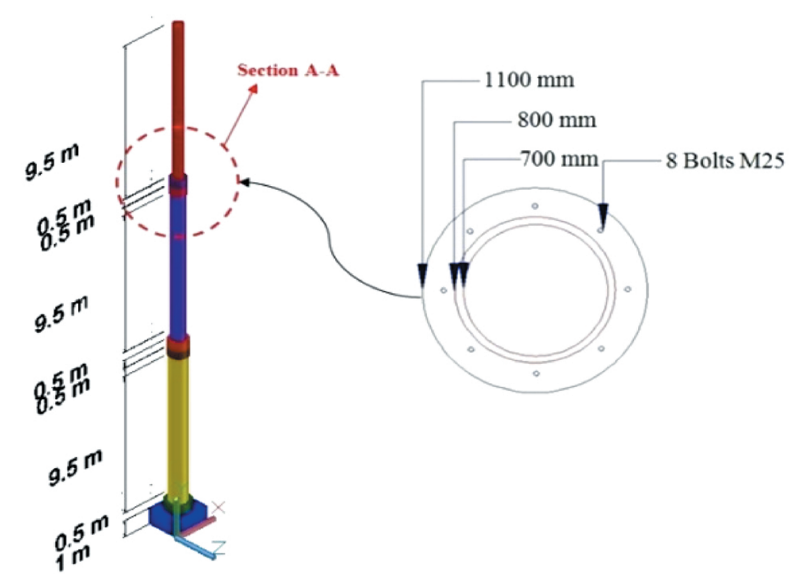

(a)

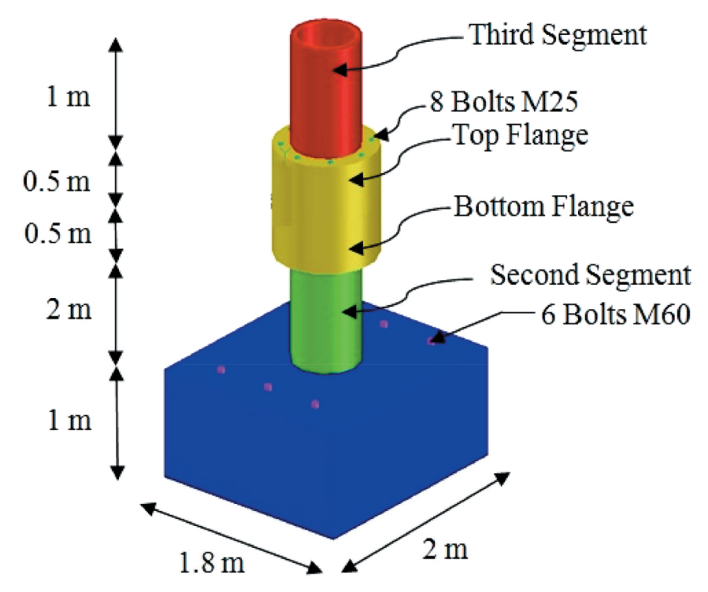

(b)

Fig. 7 The considered top connection for testing

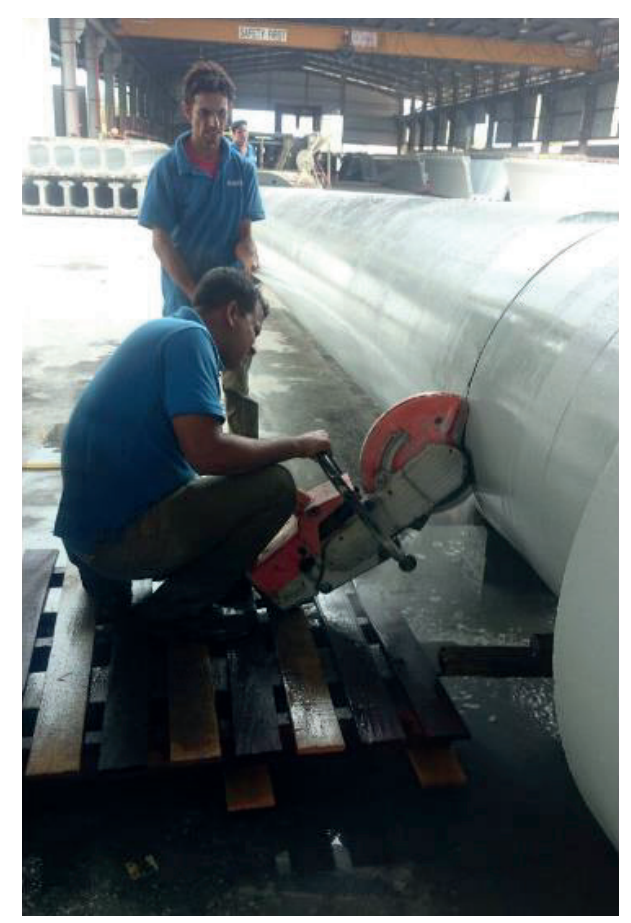

Fig. 8 Cutting the CFBC with segments sections from the real tower 


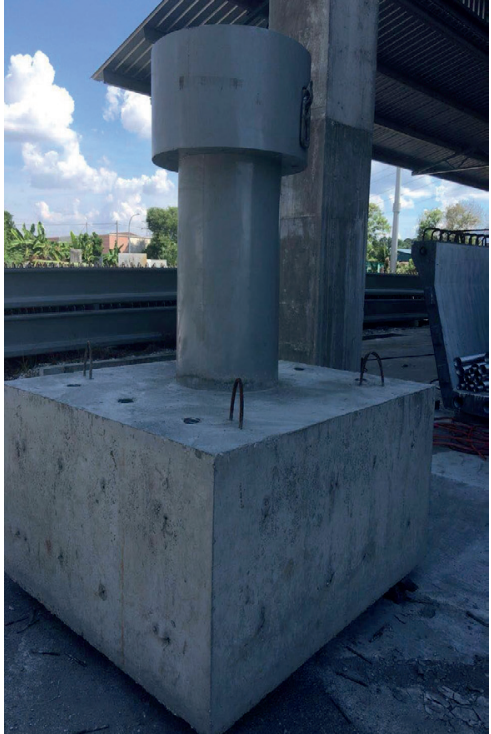

Fig. 9 The top section of the second segment and its connection cast to the foundation

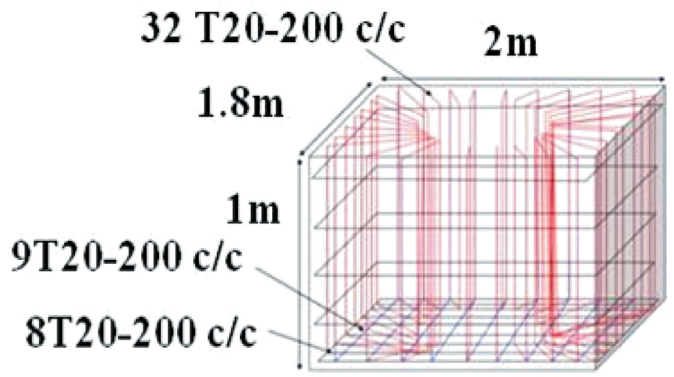

(a)

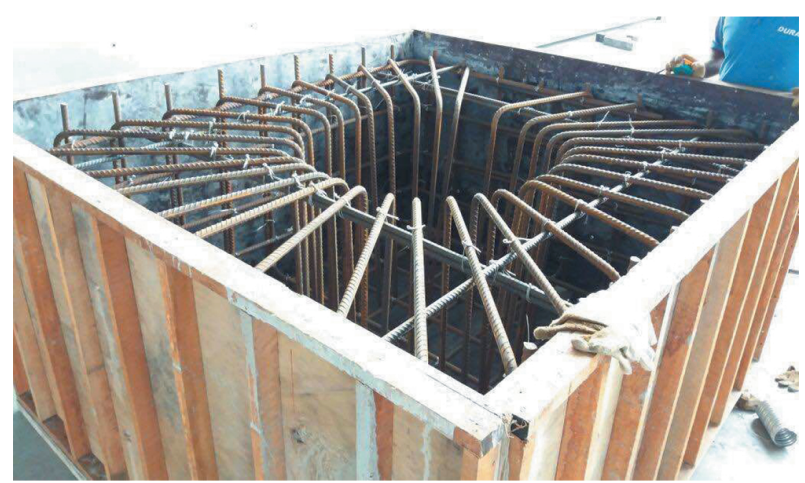

(b)

Fig. 10 Tower's foundation reinforcement details

In order to increase the strength of the tower foundation against the tensile stresses, 4T20-200 c/c of horizontal reinforcement was used to reinforce the foundation. Also, the foundation was reinforcedvertically with $U$ shape reinforcement 9T20-200 c/c along the long side and 8T20$200 \mathrm{c} / \mathrm{c}$ along the short side to increase the stability of the foundation against the horizontal shear forces. In addition, 32 vertical stirrups of T20-200 c/c were used to reinforce the whole foundation in all sides as shown in Fig. 10.

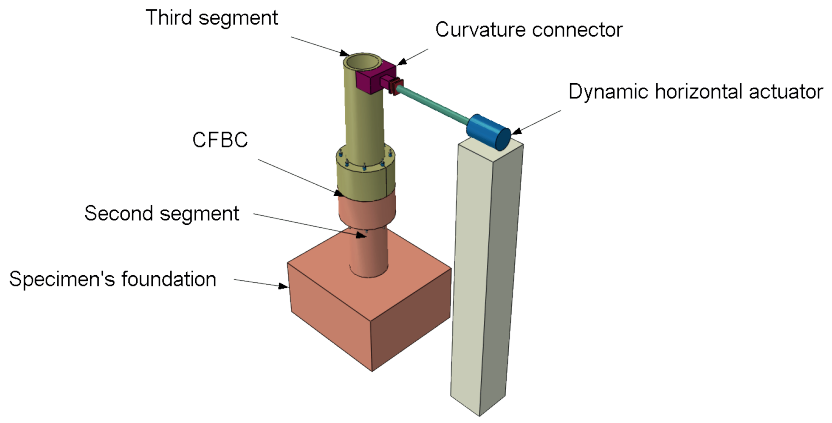

Fig. 11 The test setup of base connection

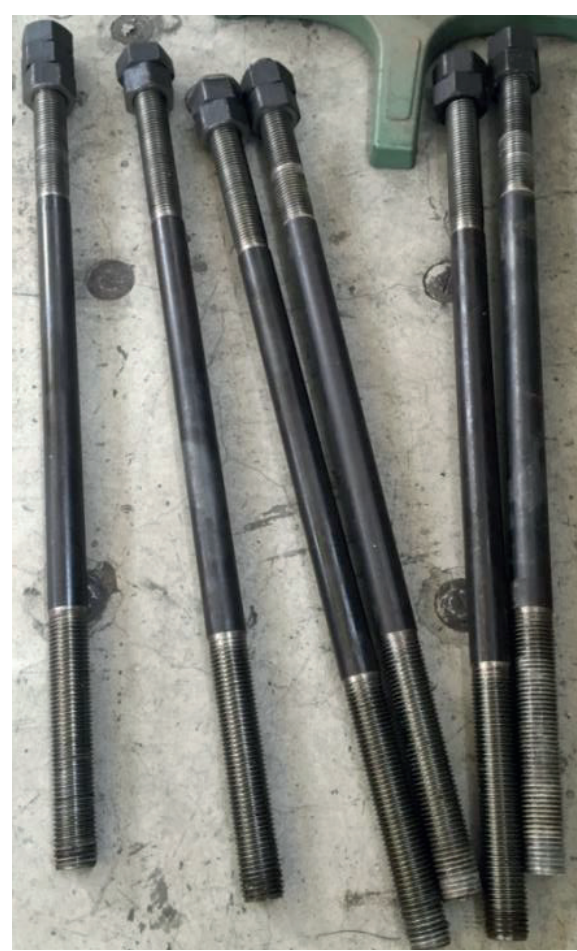

Fig. 12 The bolts used for fixing the foundation on the rigid floor of the lab

The experimental test was carried out on the connection section by applying cyclic displacement laterally with $0-150 \mathrm{~mm}$ amplitude on the top of the hollow segment representing cyclic load with a dynamic actuator of $300 \mathrm{kN}$ capacity as shown in Fig. 11.

The experimental test setup was constructed by locating and tying the specimen to the rigid floor of the structural lab with the aid of bolts. Six M60 bolts of $1500 \mathrm{~mm}$ length were used to fix the specimen to the foundation (lab floor) as shown in Fig. 12. Before commencement of the test, the hydraulic pump pressure for dynamic actuator of $300 \mathrm{kN}$ capacity was set at $20 \mathrm{MPa}$ and time history data was applied through actuator as cyclic displacement at the top of the tower Fig. 13 segment in accordance with ATC [32] as shown in Fig. 14. 


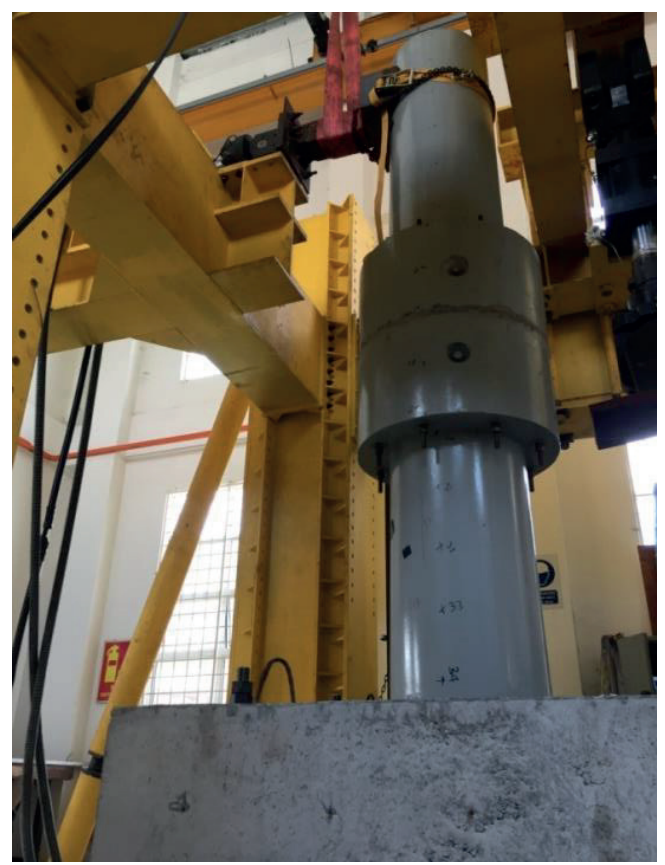

Fig. 13 Testing the top connection

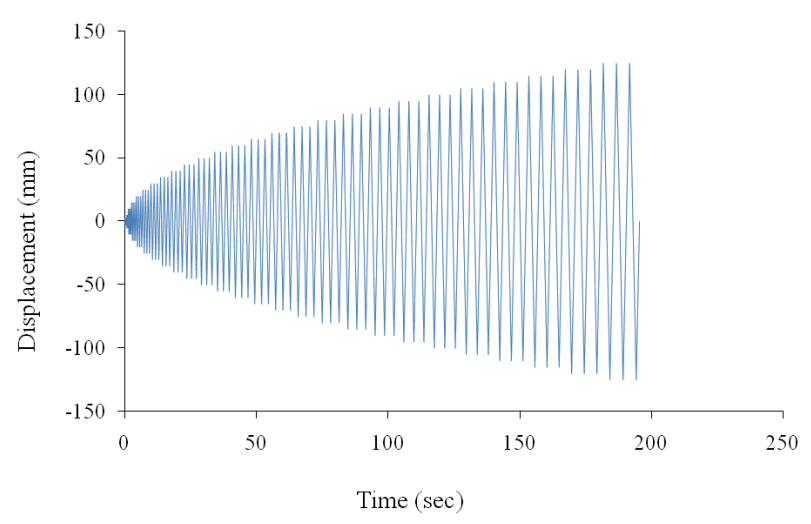

Fig. 14 Displacement time-history data [32]

\subsection{Failure mode during loading}

The force applied on the specimen has been transmitted through the tower body in the third segment to the connection and then second segment. Then, the force was transferred to the foundation which showed an adequate capacity during the load transfer. By applying the cyclic displacement, the first crack appeared at $38 \mathrm{kN}$ force in the hollow section of the bottom segment and the tower was deformed at $9.5 \mathrm{~mm}$ displacement imposed to the segments. The second crack appeared in the hollow section of the bottom segment at $58 \mathrm{kN}$ force at about $14 \mathrm{~mm}$ displacement. It was observed that the $75 \mathrm{kN}$ force caused crack in the bottom segment in $25 \mathrm{~mm}$ displacement of a $125 \mathrm{~mm}$ as shown in Fig. 15(a). Further cracks were initiated at $95 \mathrm{kN}$ which have been generated at $29 \mathrm{~mm}$ displacement due to the occurring of tension failure at some sections of the tower subjected to lateral loading. Furthermore, it has been observed that at $98 \mathrm{kN}$ some diagonal and vertical cracks were developed in both the bottom and the top segments along with few fine cracks in the flange of the top segment, as shown in Fig. 15(b) because of the occurring of shear and tension failure modes in the connection components. Moreover, diagonal cracks appeared at the force of $123 \mathrm{kN}$ at the $35 \mathrm{~mm}$ applied displacement due to shear failure in the area of crack. When the applied displacement was $50 \mathrm{~mm}$, a flexural crack was propagated horizontally in the hollow segment section at force of $151 \mathrm{kN}$.

Then few cracks were propagated vertically at the top hollow segment of the tower at the force of $170 \mathrm{kN}$ with $65 \mathrm{~mm}$ applied displacement, as shown in Fig. 15(c) due to tension damage in the segment. In addition, the $72 \mathrm{~mm}$ displacement caused $180 \mathrm{kN}$ force and some horizontal cracks in the bottom and the top segment as well due to flexural failure which means that the applied moment reaches the cracking moment (Mcr) of the connection's segments. Finally, at $188 \mathrm{kN}$ force some horizontal fine cracks have been occurred at the top and the bottom segments and also in the applied epoxy place, as shown in Fig. 15(d) due to flexural failure. The results showed that the UHPFRC didn't have reached the material yield limit. As a result, the integrity and stability of tower segment were not affected by the appearance of the cracks as it continued to resist the applied load. Furthermore, the tower showed high integrity and the structure was considered safe even with the pushed displacement of $125 \mathrm{~mm}$. According to the experimental test, applied epoxy in the joint resisted up to $188 \mathrm{kN}$ force. However, after increasing the load, the epoxy which was in contact with the surface to two segments were cracked. Meanwhile, the bolts in the joint were observed provided enough integrity for the connection in higher force. Furthermore, the bolts connecting the tower to the foundation were damaged at beginning of the test Fig. 16 as result of the shear forces and moments generated in the foundation and the lateral forces acting during the pushing and pulling processes but it didn't affect the test results. The bolt failure in the connection was due to the limited strength of the rigid floor. From calculated test, it could be concluded that the CFBC showed good performance during applied lateral forces to the UHPFRC tower. No permanent bending or deformation of the connection and tower segment were recorded after experimental connection tests had failed in conformity with the design. 


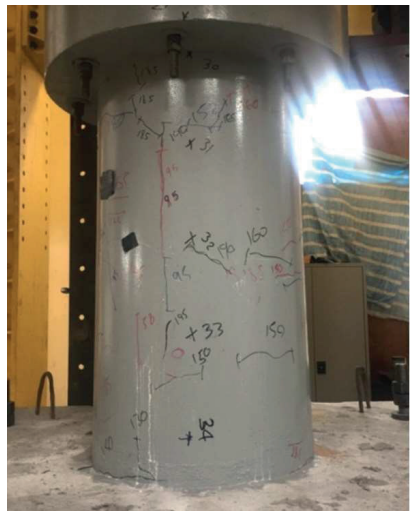

(a)

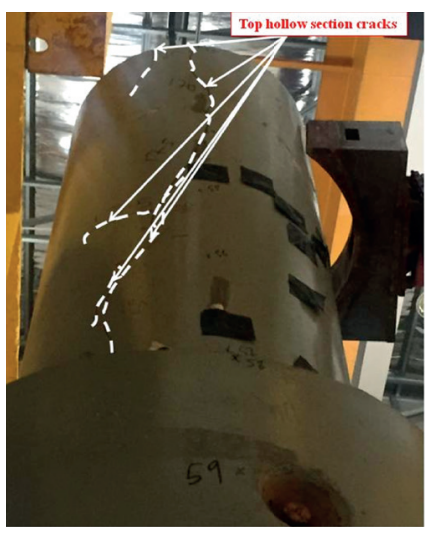

(c)

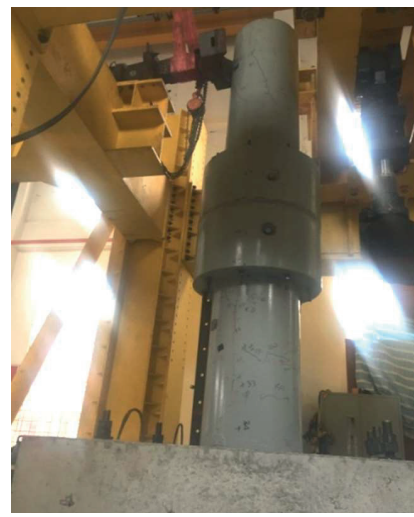

(b)

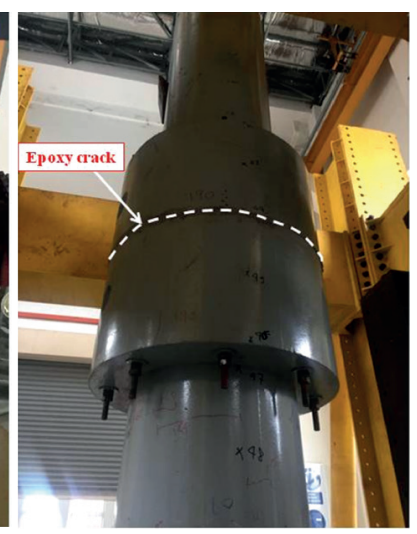

(d)

Fig. 15 The top connection after testing.

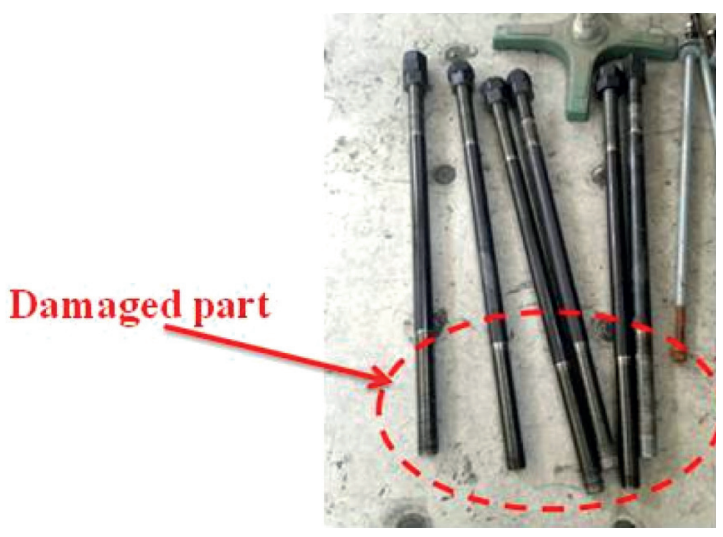

Fig. 16 Loosened bolts in the foundation

\subsection{Load and displacement}

The cyclic force-displacement curve obtained for the circular bolted connection under study is presented in Fig. 17. It is clear from the plot that specimen displayed mostly stable hysteretic behavior with gradual transition between elastic and inelastic responses. As shown in Fig. 17 that changes in reloading branch is accompanied with increment in displacement level, having to attain the same point at which the former cycle unloaded. However, irrespective of the displacement level the unloading branches were mostly parallel to each other. Results of the hysteresis loop revealed that the maximum crack force at the connection reached to $188 \mathrm{kN}$ with maximum displacement of $125 \mathrm{~mm}$. The hysteresis loop of the specimen was quite stationary showing excellent energy dissipation. The loosing of the connection between the specimen and the actuator connector after few cycles caused small resistant forces at the beginning of the test. In addition, the loosened connection between the specimen and the rigid floor caused the specimen slide laterally during the test because of the limit capacity of the rigid floor. This led to flattening of the hysteresis loops during the load reversal due to the reduction in specimen fixing.

According to the backbone curve, the influence of construction details on ultimate lateral strength, initial stiffness, deformation capacity as well as secant stiffness could be seen. Then, the specimen began to exhibit strength loss due to bolt loosening between the specimen and the floor. The specimen behaved linear until cracks began to develop at the epoxy between the flanges resulting to softening in the lateral stiffness.

Although the marginal cracks appeared in the circular hollow segments of the specimen, the connection and tower segments showed appropriate integrity after the experimental testing process. The $\mathrm{CFBC}$ could show higher resistance force but the experimental test has been stopped due to failure in foundation's bolts. The comparison between the results of experimental test and calculated design force caused by earthquake and wind loads for the bolted connection showed that the maximum force and displacement capacity from the experimental results are higher than the required designed force and allowable displacement, as shown in Table 4. Meanwhile, the top connection proved to be stable and sufficiently reliable against lateral shear forces and generated moments during the applied load.

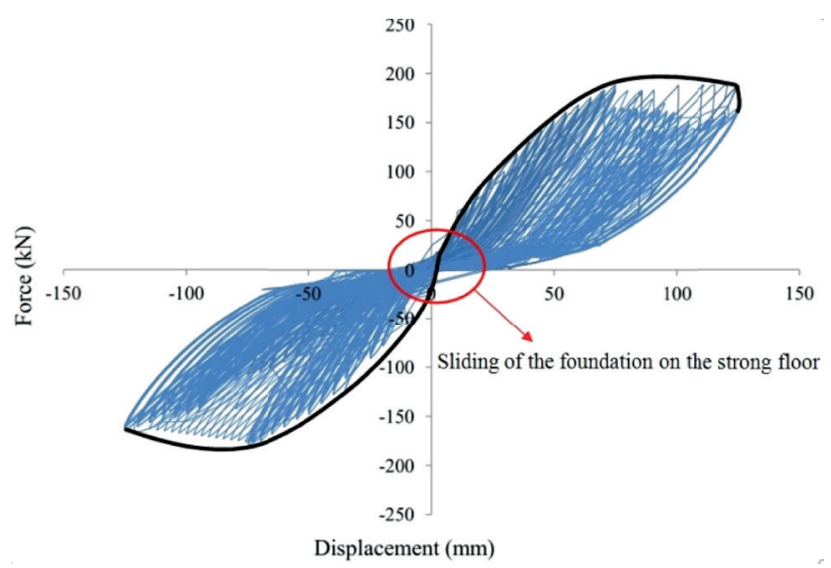

Fig. 17 Experimental cyclic test's result 
Table 4 The comparison between the design calculations and the experimental study for the CFBC

\begin{tabular}{|c|c|c|c|c|c|c|c|c|}
\hline \multicolumn{4}{|c|}{ Design Calculations } & \multicolumn{5}{|c|}{ Experimental Testing } \\
\hline $\begin{array}{l}\text { Type of } \\
\text { Design }\end{array}$ & $\begin{array}{c}\text { Ultimate/ } \\
\text { Serviceability } \\
\text { Limit State }\end{array}$ & $\begin{array}{l}\text { The Design } \\
\text { ShearForce } \\
(\mathrm{kN})\end{array}$ & $\begin{array}{c}\text { The Design } \\
\text { Moment } \\
\text { (kN.m) }\end{array}$ & $\begin{array}{l}\text { Allowable } \\
\text { Displacement } \\
(\mathrm{mm})\end{array}$ & $\begin{array}{c}\text { Shear } \\
\text { Resistant } \\
\text { Force }(\mathrm{kN})\end{array}$ & $\begin{array}{c}\text { Moment } \\
\text { Resistant } \\
\text { Force (kN.m) }\end{array}$ & $\begin{array}{l}\text { The Maximum } \\
\text { Displacement } \\
(\mathrm{mm})\end{array}$ & Comparison \\
\hline \multirow{2}{*}{$\begin{array}{l}\text { Design for } \\
\text { Wind Load }\end{array}$} & $\begin{array}{l}\text { Ultimate limit } \\
\text { state }\end{array}$ & 13 & 61 & $\frac{h}{500}=\frac{2000}{500}=$ & $\mathrm{F}=189$ & $\begin{array}{l}M=P \times L \\
=189 \times 4\end{array}$ & $\mathrm{D}=125$ & $\begin{array}{c}\text { F: } 189>\text { all } \\
\text { design forces } \\
\sqrt{\text { OK }}\end{array}$ \\
\hline & $\begin{array}{l}\text { Serviceability } \\
\text { Limit State }\end{array}$ & 9.35 & 44 & $=4 \mathrm{~mm}$ & & $=756$ & & $\begin{array}{c}\text { M: } 756>\text { all } \\
\text { design moments }\end{array}$ \\
\hline \multirow{2}{*}{$\begin{array}{l}\text { Design for } \\
\text { Earthquake } \\
\text { Load }\end{array}$} & $\begin{array}{l}\text { Ultimate } \\
\text { Limit State }\end{array}$ & 12.5 & 58 & & & & & $\sqrt{ } \mathrm{OK}$ \\
\hline & $\begin{array}{c}\text { Serviceability } \\
\text { limit state }\end{array}$ & 8.89 & 42 & & & & & $\begin{array}{c}\text { D: } 125>4 \\
\sqrt{ } \text { OK }\end{array}$ \\
\hline
\end{tabular}

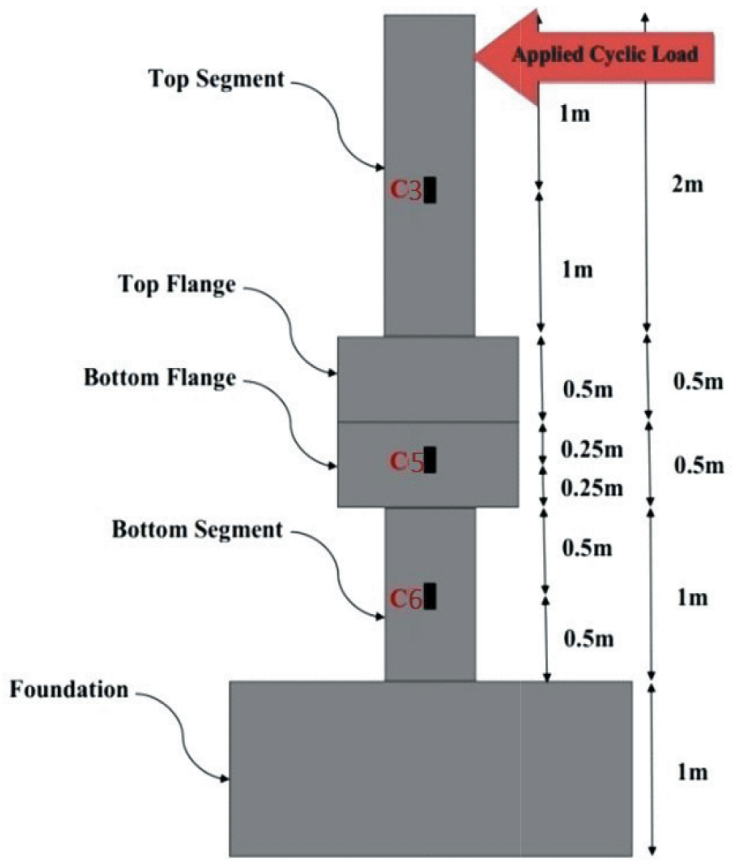

(a)

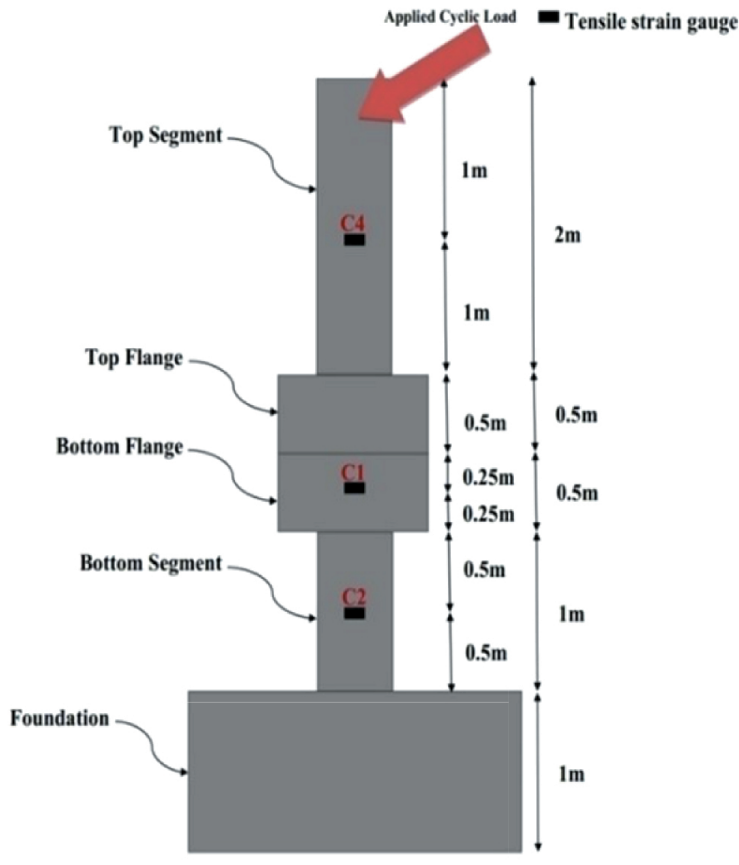

(b)

Fig. 18 Location of strain gauges at the RC models for the side face (Tension strain gauges) and the forcing face (Shear strain gauge)

\subsection{Strain gauge results}

Fig. 18 shows positions of strain gauges on the concrete surface. Six concrete strain gauges were attached to the smooth concrete surface with the aid of standard rapid adhesive. Three strain gauges designated as C3, C5 and C6 were placed vertically at the specimen side in order to measure the tension strain in the connection and the hollow tower. At the load application direction, three strain gauges $\mathrm{C} 4, \mathrm{C} 1$ and $\mathrm{C} 2$ were placed horizontally at the specimen for shear strain measurement in the connection and tower.

The strain gauge results show that the maximum shear strains is the top and the bottom sides of the hollow segments where the load was applied. The maximum shear strain of $717.34 \mu \mathrm{m} / \mathrm{m}$ was recorded at strain gauge C2 which indicates that most of the deformations were in the bottom hollow segment. It has noticed from the results that strain gauge $\mathrm{C} 2$ has stopped recording at $717.34 \mu \mathrm{m} / \mathrm{m}$ as shown in Fig. 19(b). This indicates that C2 has damaged during the testing due to the movement of the tower especially in the bottom tower segment. Besides, the other strain gauge (C6) attached horizontally at the top hollow segment on the side of segment where the load was applied has recorded maximum shear strain of $606.5 \mu \mathrm{m} / \mathrm{m}$ in the top segment as shown in Fig. 19(d). On the other specimen's side, the maximum strain was in the bottom hollow segment tower which has been recorded by strain 


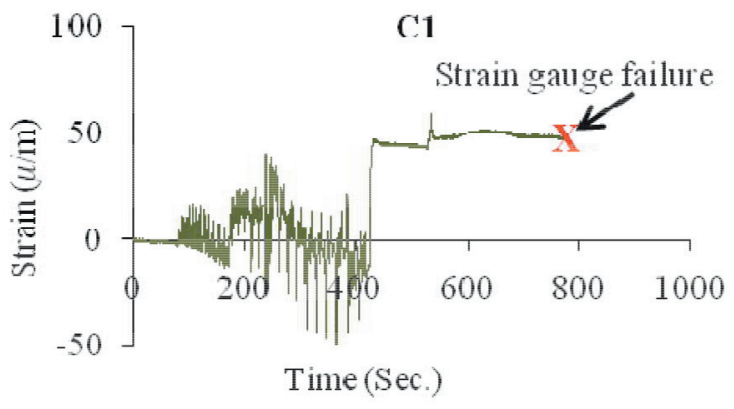

(a)

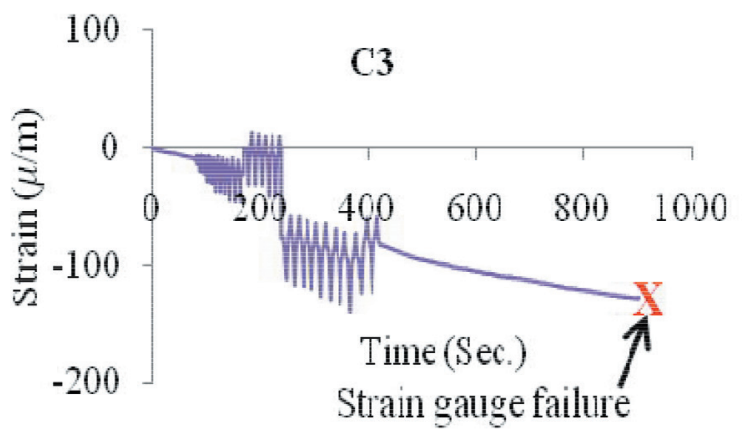

(c)

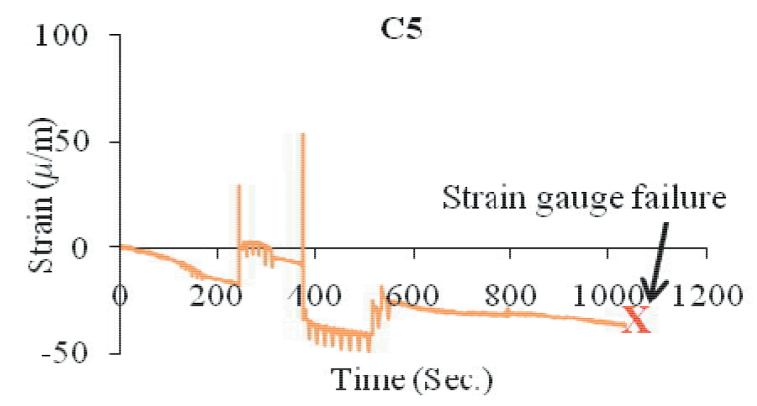

(e)

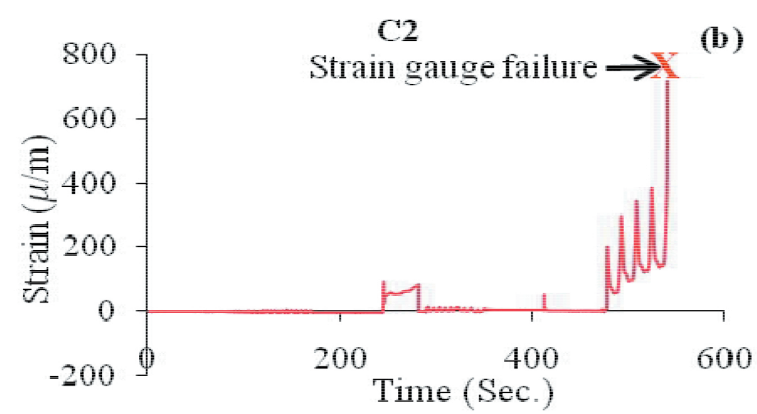

(b)

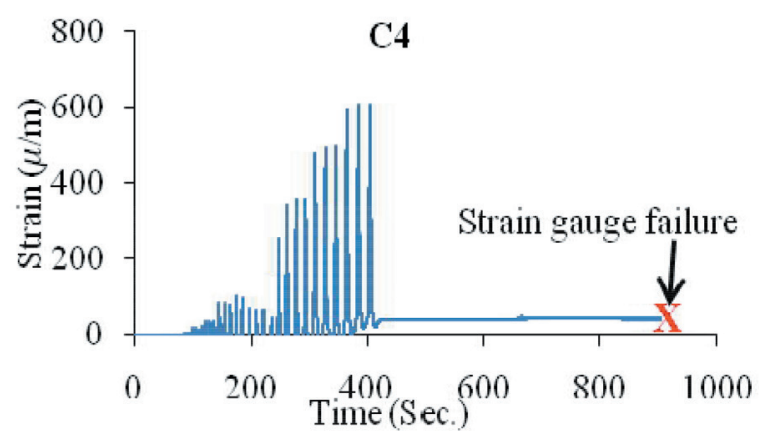

(d)

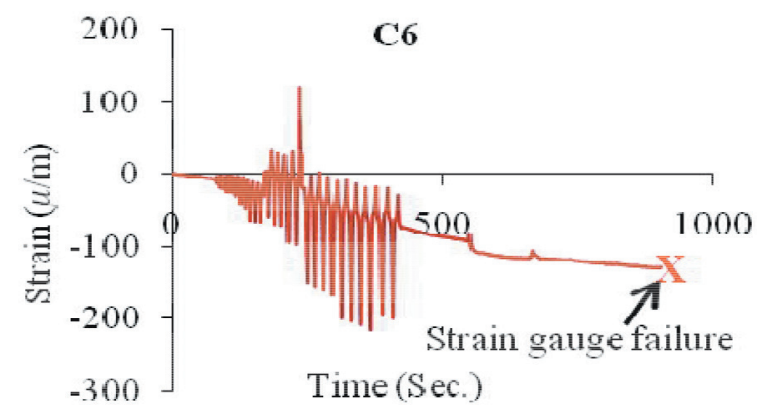

(f)

Fig. 19 The results for strain gauges

gauge $\mathrm{C} 6$. It means that the maximum strain in the bottom segment was $-215.8 \mathrm{~m} / \mathrm{m}$ indicating a compression strain on the specimen side as shown in Fig. 19(f). Also, strain gauge C3 in the top hollow segment recorded maximum compression strain of $-139.4 \mathrm{~m} / \mathrm{m}$ on the specimen side as shown in Fig. 19c.

For the connection section, it was found that the maximum strains in the bottom flange connection were $58.7 \mathrm{~m} / \mathrm{m}$ and $-68.5 \mathrm{~m} / \mathrm{m}$ on the force application direction and on the side face of the specimen, respectively as shown in Fig. 19(a) and 19(e). The results showed that the CFBC joint were the most rigid section in the specimen. It was noticed from the results that by increasing of the amplitude of the cyclic load, the shear and tension strains were increased.

\section{Finite element modeling}

\subsection{Geometric modeling}

In order to verify the experimental results, FEM was used for the numerical modelling and analysis of the considered specimen. The numerical simulated model of the CFBC was developed in accordance with the dimensions of the real model as shown in Fig. 20. The CFBC model includes the top $1000 \mathrm{~mm}$ of the second segmental tower connected with the first $1500 \mathrm{~mm}$ of the third segmental tower by using two $500 \mathrm{~mm}$ thickness flanges (cast together with the hollow segments) with 8M25 steel bolts and epoxy resin. A prestressed tendon of grade 270 eight wire strands $(270 \mathrm{ksi}=1861 \mathrm{MPa} ; \mathrm{E}=196.5 \mathrm{GPa}$; and area of $1600 \mathrm{~mm}^{2}$ ) was placed at the circumference of the hollow section of the tower. 


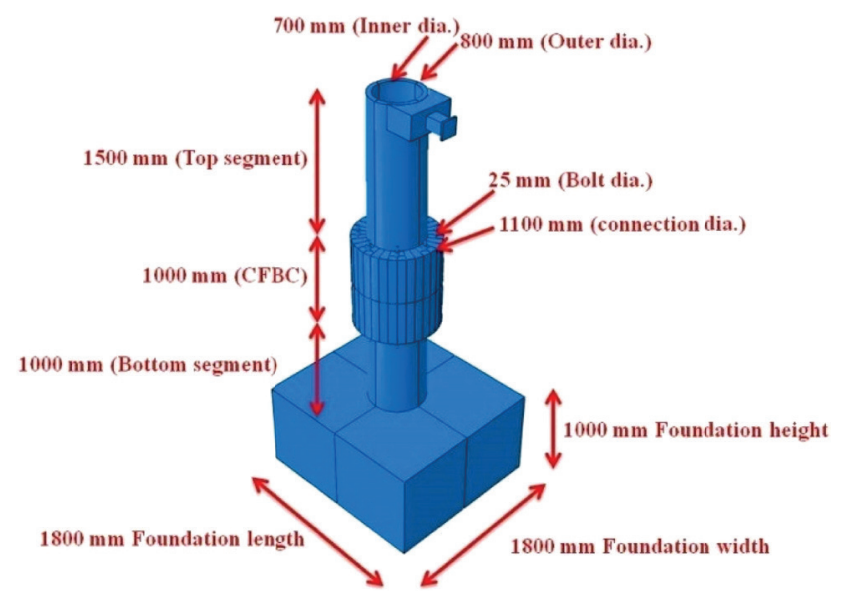

Fig. 20 Top connection in the ABAQUS (with details)

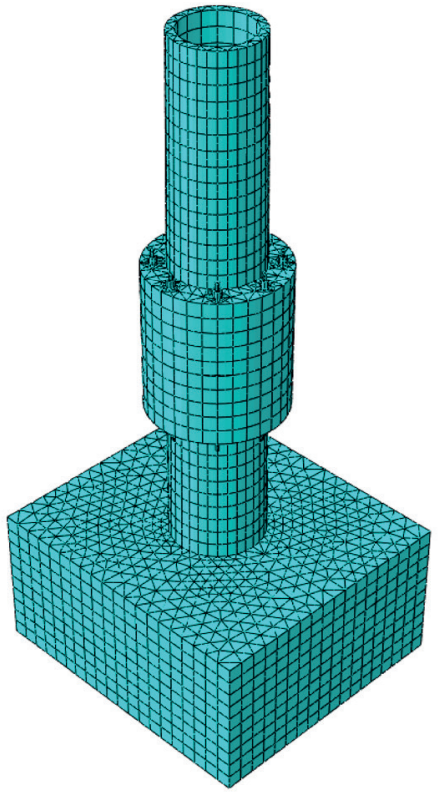

Fig. 21 Meshed FE model of the CFBC

The FE model was developed using ABAQUS, having considered necessary conditions likely to affect the accuracy of the examination (material properties; appropriate selection of element type and mesh size; loadings and boundary conditions as well as rational setting of analysis procedures; etc.)

The proposed models were meshed with the aid of assigned mesh tool with controlled element size to capture the stress distribution over the process of loading. In the current study, the connection was modelled using reduced-integration 20-noded plain stress elements (C3D20R). The UHPFRC connection and the steel wires section were meshed using element size $15 \mathrm{~mm} 100 \mathrm{~mm}$ respectively. The meshed model of the cycling test is shown in Fig. 21. Considering the shape complexity of cylindrical model elements, sweep mesh was used for circular shape elements.
Table 5 Material properties of UHPFRC and Steel (MPa)

\begin{tabular}{|c|c|c|c|c|}
\hline \multicolumn{5}{|l|}{ Concrete } \\
\hline Specimen & $\begin{array}{l}\text { Poisson } \\
\text { ratio }(v)\end{array}$ & $\begin{array}{c}\text { Elastic } \\
\text { modulus }\left(E_{c m}\right)\end{array}$ & $\begin{array}{l}\text { Compressive } \\
\text { strength }\left(f_{c}\right)\end{array}$ & $\begin{array}{c}\text { Tensile } \\
\text { strength }\left(f_{t}\right)\end{array}$ \\
\hline Connection & 0.2 & 50000 & 200 & 19.3 \\
\hline \multicolumn{5}{|l|}{ Steel } \\
\hline Specimen & $\begin{array}{l}\text { Poisson } \\
\text { ratio }(v)\end{array}$ & $\begin{array}{c}\text { Elastic } \\
\text { modulus }\left(E_{c m}\right)\end{array}$ & $\begin{array}{l}\text { Yielding } \\
\text { strength }\left(f_{c}\right)\end{array}$ & $\begin{array}{c}\text { Ultimate } \\
\text { strength }\left(f_{t}\right)\end{array}$ \\
\hline $\mathrm{RC}$ & 0.3 & 200000 & 340.7 & 450 \\
\hline $\begin{array}{l}\text { Strand } \\
\text { cables }\end{array}$ & 0.3 & 196500 & 1450 & 1860 \\
\hline Bolts & 0.3 & 200000 & 410 & 510 \\
\hline
\end{tabular}

\subsection{Material properties}

Material properties of the concrete and steel members used in the experiment are obtained from material tests as given in Table 5 and were used in the FE analysis. The strain-stress curve was assigned to the FE models by specifying the ultimate strength, yield strength, as well as the elastic modulus.

The material properties of UHPFRC used in FE software were obtained according to the Japanese code JSCE [33]. The uniaxial concrete tensile and compressive strengths $\left(f_{t}\right)$ and $\left(f_{c}\right)$ were respectively employed to define failure criteria of the concrete particularly crushing and cracking patterns in the concrete.

\subsection{Contact modeling}

Contact elements were employed to model the interactions between steel and concrete elements and between concrete and concrete elements. Again, the surface-to-surface contact was used between the top hollow flange segments and the bottom hollow flange segments. The bottom hollow segment in contact with the flange and the foundation are chosen as master surface, while the top hollow segment in contact with the flange are set as the slave surface. Besides, the embedded region constraint was used for reinforcement (RC) and strands with the concrete. The $\mathrm{RC}$ and the strands are chosen as embedded region, while the concrete is set as the host region. In addition, the tie constraint was used between bolts and the concrete. The bolts were chosen as master surface while concrete was set as the slave surface.

\subsection{Boundary conditions and loading}

For the support boundary condition the specimen was set to be rigidly fixed at the base. Hence, the FE model restrained all degrees of freedom at the base (support) of the specimen. In this study, effective prestressing force 
$(\mathrm{Pe}=2667.2 \mathrm{kN})$ and displacement are applied on the CFBC. The displacement was applied as load on a curvature plate attached to the top section of the upper hollow concrete segment in the FE model as shown in Fig. 22. The total amount of displacement of $125 \mathrm{~mm}$ was divided into a number of sub-steps to simulate the incremental load applied in the cycling test while the automatic time stepping was activated to ensure the usage of optimum load increment whenever the nonlinear behavior occurs as shown in Fig. 14. The time history data were used in accordance with ATC code [32].

\section{Finite Element analysis (FE) \\ 6.1 Hysteretic response}

After conducting the analysis using FE software, the CFBC joint in the UHPFRC tower showed very high strength capacity. The high shear capacity of the connection was due to the high strength of UHPFRC material reinforced with high-tensile steel fibers in the CFBC joint. Analysis results of FE showed that the UHPFRC connection with a total height of $4.5 \mathrm{~m}$ can resist forces up to $216.6 \mathrm{kN}$ and displacement of $231.3 \mathrm{~mm}$ as showed in Fig. 23.

\subsection{Energy dissipation curve}

High energy dissipation is a desirable property whenever a structure is subjected to a severe seismic event. The amount of energy dissipated per cycle is equal to the area within the lateral load versus displacement hysteresis curve of this cycle. Fig. 24 shows a plot of cumulative energy

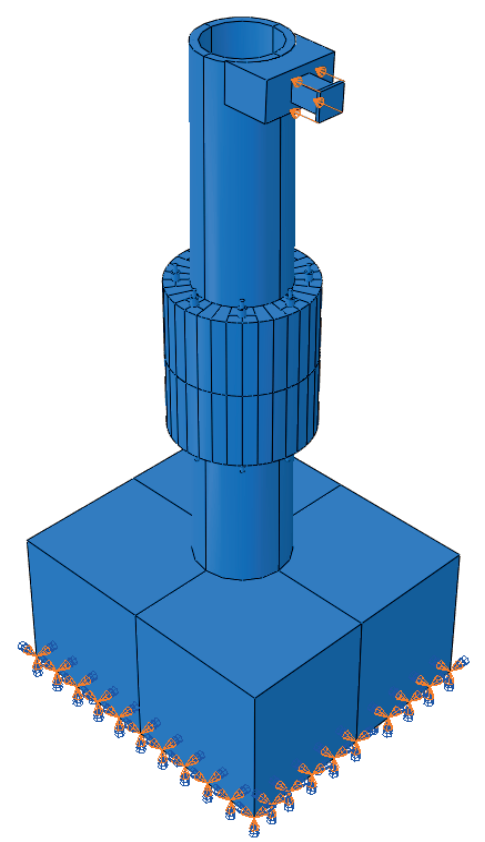

Fig. 22 The top connection with $125 \mathrm{~mm}$ amplitude displacement dissipated versus cycle number. It indicates that the UHPFRC circular connection specimen dissipated highest amount of hysteretic energy due to the existence of the steel bolts, high strength of the UHPFRC and the design method. The amount of energy dissipation that the UHPFRC circular bolted flange offers gives reason to explore more viable and reliable connections in order to maximize the potential of a CFBC. It is therefore apparent from this and other research that the concept of CFBC is one which should be explored more rigorously. According to the results, UHPFC circular bolted connection show more ductile failure patterns which allowed large energy dissipation thus resulting to slower crack speed under slow loading rates. In the current study the maximum energy dissipation of UHPFRC circular bolted connection is 107 kN.m according to Eq. (1) [34] as shown in Fig. 24.

$W=\frac{1}{2} \times X_{\max } \times D_{\max }$

To realize the failure pattern in the FE model, components which might have failed could be identified by examining values of stresses in the different components at ultimate load and comparing with the ultimate stress defined for different materials. The proposed FE model revealed

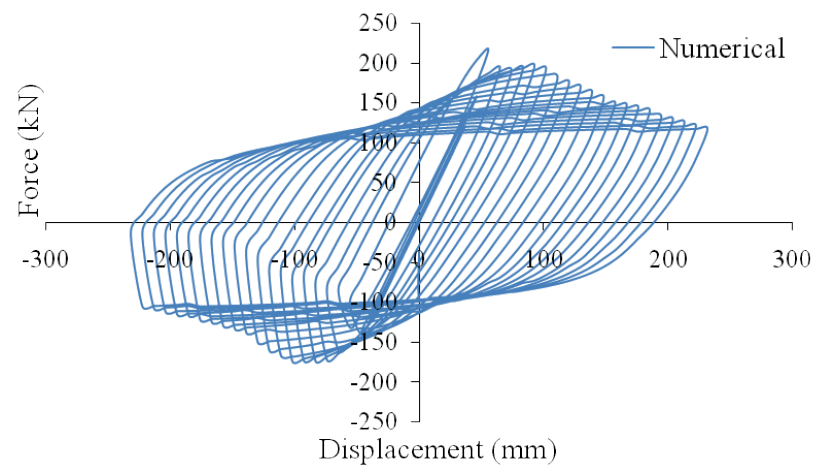

Fig. 23 Numerical force-displacement results

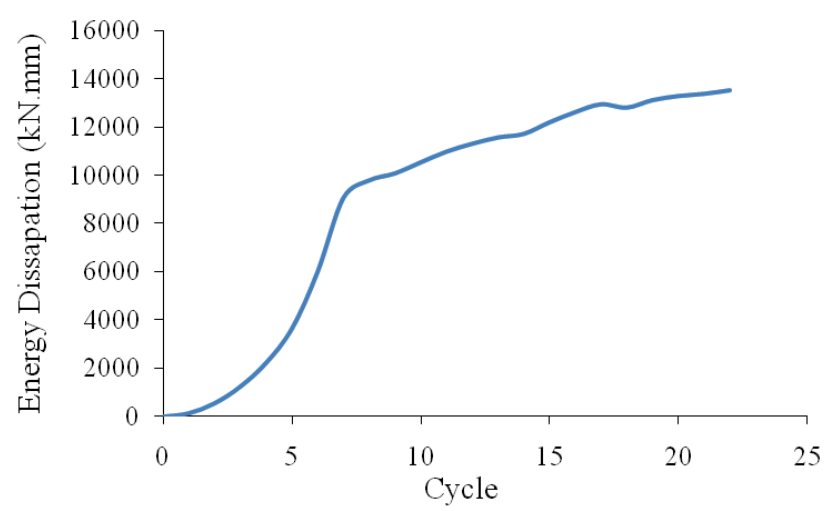

Fig. 24 Energy dissipation curve 
that some structural components remained elastic whilst others had assumed values of stresses close to their ultimate stresses which were considered to have failed. It was also observed that for both edges of the hollow segments had approximately reached their ultimate stresses. The position of these stresses was consistent with experimental observations Fig. 25.

Fig. 25(a) to (d) illustrates the stress contour plots derived from the finite element analysis for the connection model $\left(f_{c}=200 \mathrm{~N} / \mathrm{mm}^{2}\right)$ which include the von Mises stress. These plots clearly illustrate the both zones of compression and tension within the connection specimen, i.e. the CFBC, under a lateral load. The envelope of Mises stress of CFBC showed that the maximum equivalent stress occurring at the contact area between the circular hollow segments and the specimen's foundation is $154 \mathrm{MPa}$, which is smaller than the material yield strength. The reason is because of connecting the edge of thin circular hollow segment to massive foundation make this contact a weak point during the lateral movement. However, this failure did not affect the performance of the CFBC because this contact area which had the failure was just connecting the CFBC specimen to its foundation regarding experimental testing. Since the lateral load was applied directly on the circular hollow segment's top edge, the maximum Mises stress in the top tubular segment reached $154 \mathrm{MPa}$, as shown in Fig. 25(b), which is smaller than the material yield strength. The results showed that the UHPFRC did not yield during the analysis. Whereas, the bolts of CFBC experienced maximum Mises stress of about 336.2 $\mathrm{MPa}$ in the model, as described in Fig. 25(c), indicating that the bolts were less affected by the imposed lateral loads due to the high stiffness of the UHPFRC connection's flanges. By comparing the stresses in the bolts with previous study of Blachowski and Gutkowski [7] the maximum stresses in the bolts of the current study is smaller than the maximum and the minimum stresses in the bolts of the mentioned study as illustrated in Table 6 .

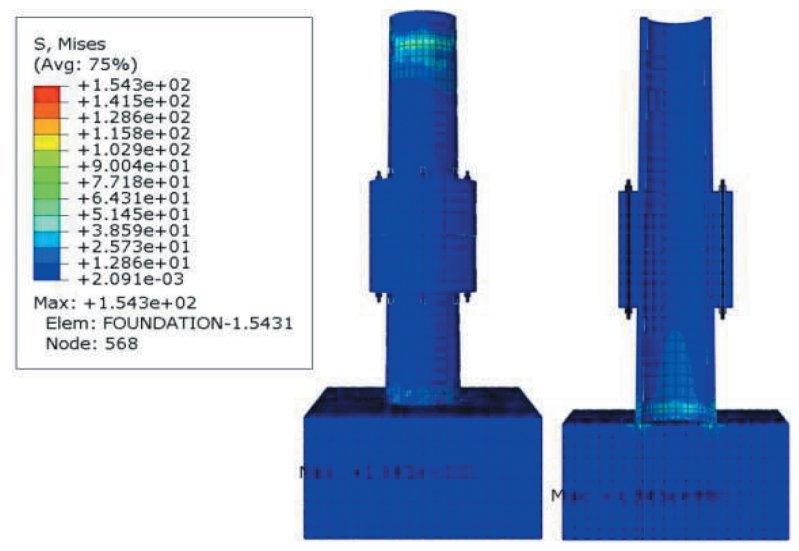

(a)

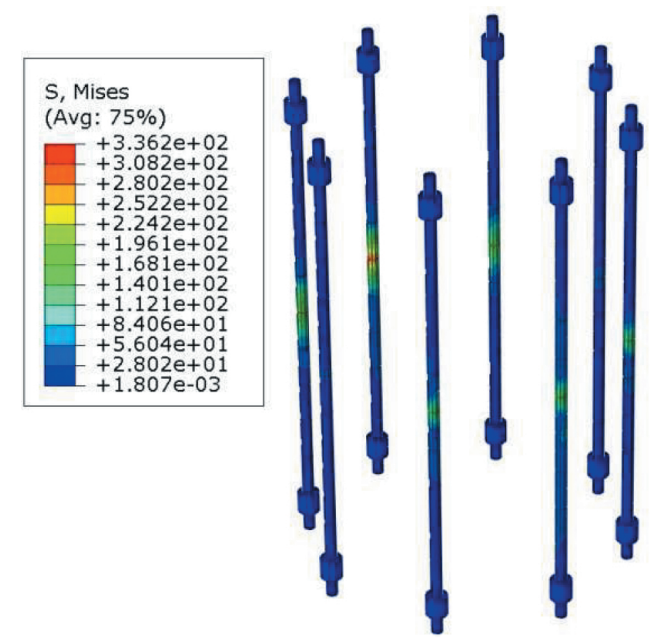

(c)
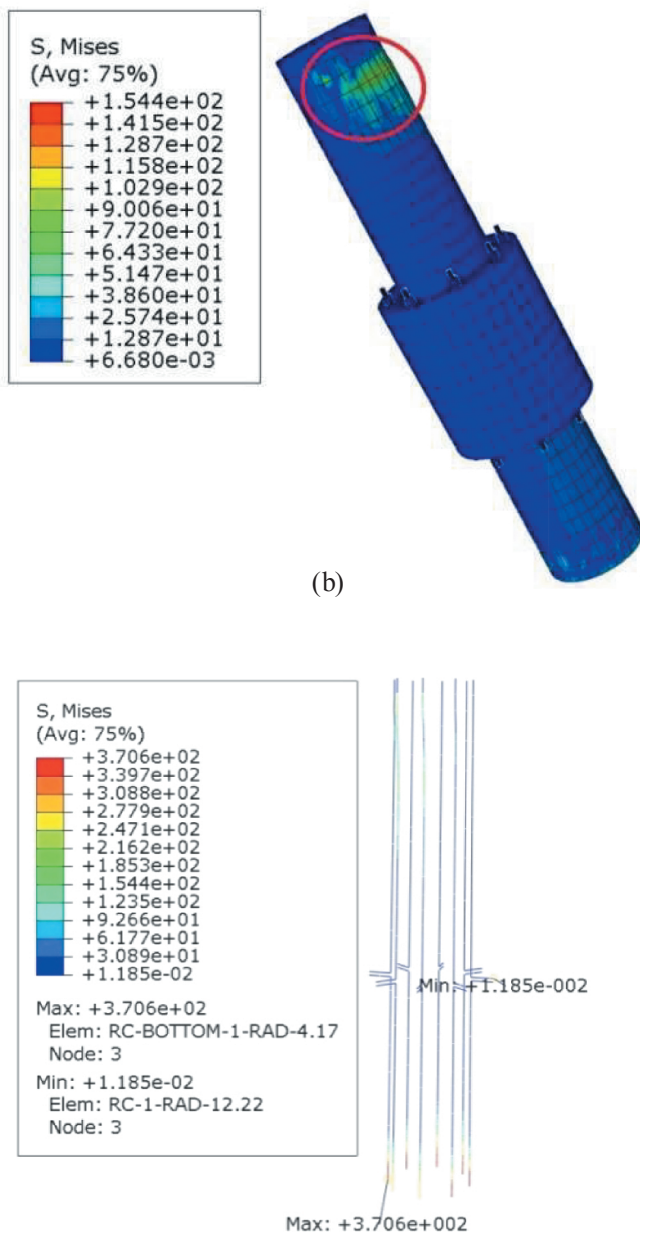

(d)

Fig. 25 Results of the stress numerical analysis 
Table 6 Max and min stresses (MPa) in bolts in UHPFRC flange and in bolts in steel flange

\begin{tabular}{lcc}
\hline & \multicolumn{2}{c}{ Bolts } \\
& CurrentStudy & $\begin{array}{l}\text { (Blachowski and } \\
\text { Gutkowskipaper) }\end{array}$ \\
\hline Bolt yield limit (MPa) & 410 & 640 \\
Bolt diameter (mm) & 25 & 20 \\
Flangematerial & UHPFRC & Steel \\
Flangethickness $(\mathrm{mm})$ & 500 & 50 \\
$\sigma_{\min }(\mathrm{MPa})$ & 0.00181 & 363 \\
$\sigma_{\max }(\mathrm{MPa})$ & 336.2 & 471 \\
\hline
\end{tabular}

This could be attributed to the high strength of the flange that resists the maximum stress which made the steel bolts less affected by the applied stress. In Table 6 , several combinations of flange thicknesses, flange material, bolt diameter and bolt yield limit. It is worthy of note, that bending of bolts have a substantial influence on structural well-being. The bending effect is largely dependent on flange thickness. As a particular case the magnitude of stresses for flange thickness of $500 \mathrm{~mm}$ is under yield limit. In addition, the maximum Mises stress in the steel reinforcement reached 370.6 MPa which is smaller than the material yield limit, as shown in Fig. 25(d) and that due to the high tensile strength of the reinforce steel during analysis.

The maximum displacement was recorded at the top node of the specimen. According to the numerical results, the maximum deformation in the top connection was $35.6 \mathrm{~mm}$ because it is the place where the load was applied directly, shown in Fig. 26(a). Since the CFBC was fixed enough in its bottom section to the rigid foundation, the minimum displacement was in the mentioned contact, as illustrated in Fig. 26(b). Besides, due to the flexibility of the UHPFRC bolted connection and the high tensile strength of the steel bolts during the cyclic movement the maximum displacement in the bolts was in the top section of the and opposite to the direction of the applied load, as described in Fig. 26(c).

Fig. 27 shows the maximum reacted forces generated in the bottom surface of the specimen's foundation because of the specimen considered fixed in the foundation bottom surface. Since the massive weight of the specimen and the applied lateral displacement by using a $300 \mathrm{kN}$ dynamic actuator, the maximum reaction forces at the fixed surface reached only $300 \mathrm{~N}$.

The numerical strain results show high similarity with the experimental results of the connection model. The mostly strain constraint at the contact between the CFBC and its foundation. Considering the movement of the bolts and in the connections between the CFBC and the specimen's

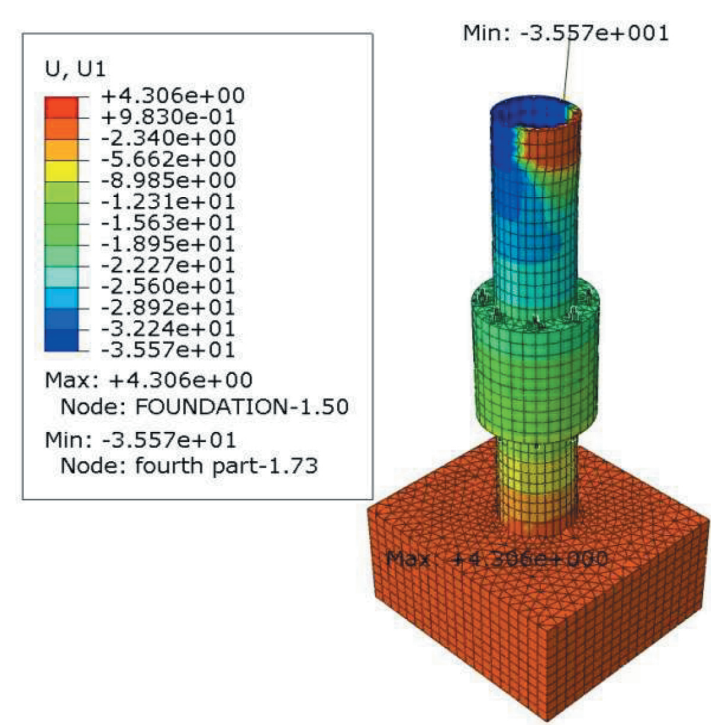

(a)

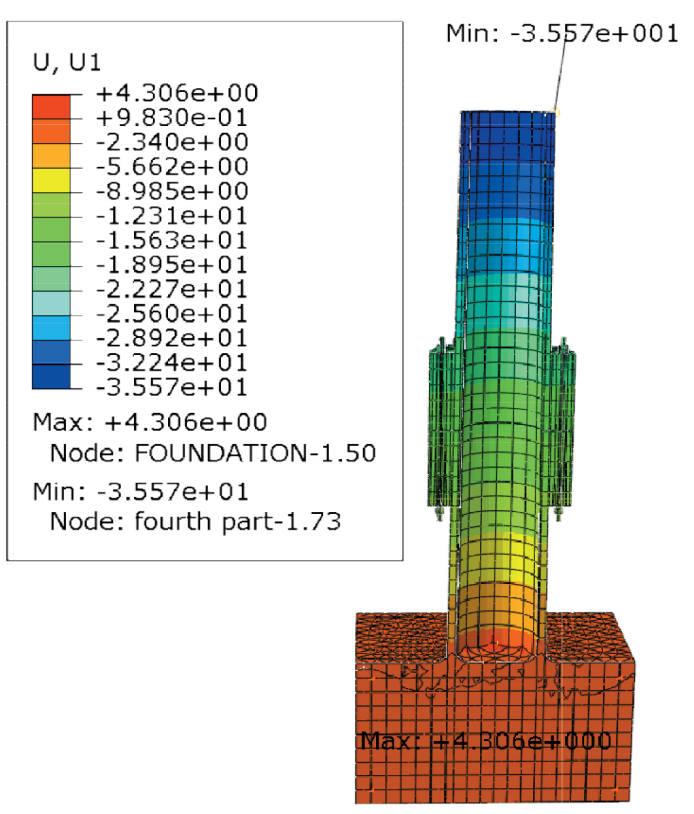

(b)

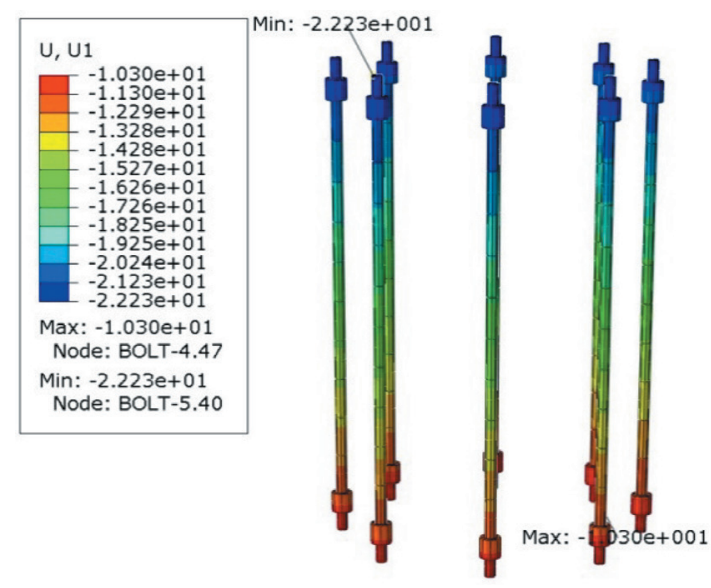

(c)

Fig. 26 Displacement numerical analysis results 
foundation, as shown in Fig. 28(a). Meanwhile, as shown in Fig. 28(b) the maximum strain in the bolts was located at the center of each bolt (i.e., the area between the connected sections) due to the rigidity of the UHPFRC flange and the massive foundation compared with the strength of the bolts the maximum strain the bolts did not reach the material yield limit. It could be seen that the numerical strain results are in accordance with the experimental results.

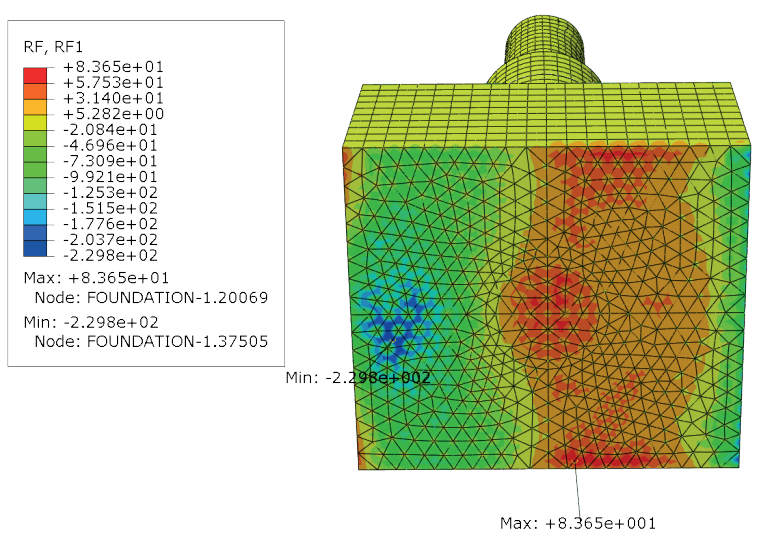

Fig. 27 Generated reaction forces in the UHPFRC connection in the horizontal direction
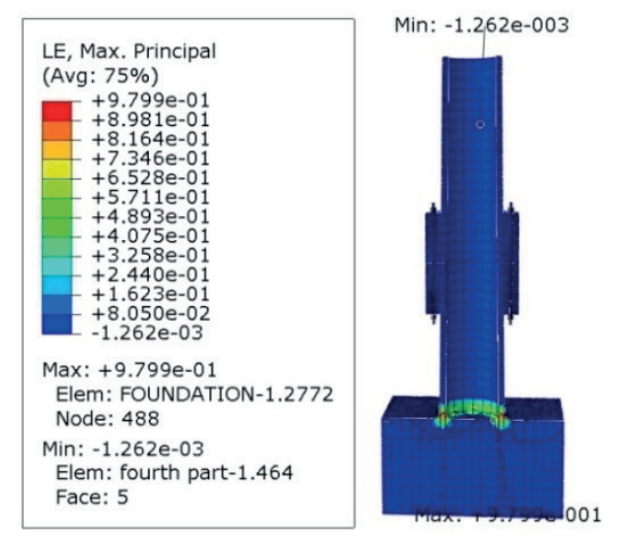

(a)
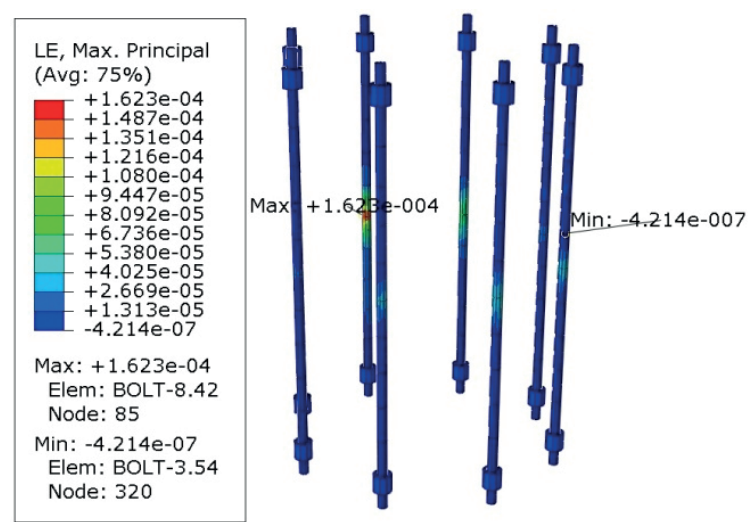

(b)

Fig. 28 Results of strain analysis for the top connection of the UHPFRC tower
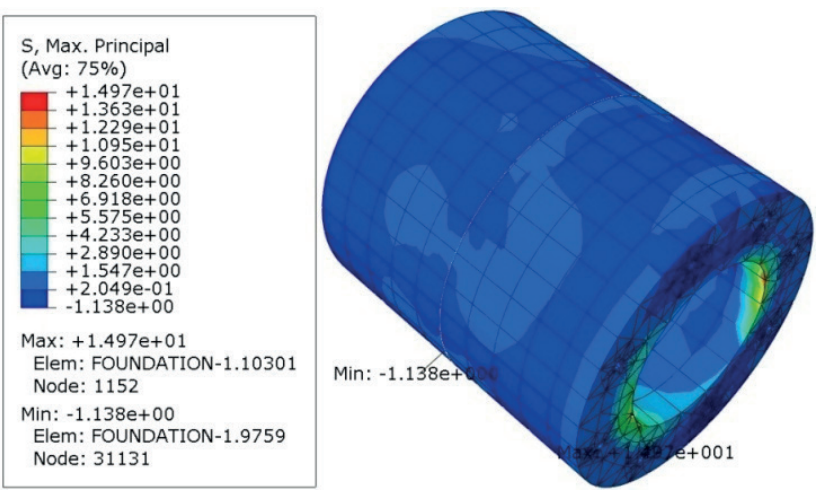

Fig. 29 Maximum stresses in the circular flange

It is worthy of note, that bending of bolts could results in a tremendous influence on structural well-being. The bending effect is largely dependent on flange thickness. The stresses due to bending are larger in the case of smaller thickness. In Blachowski and Gutkowski's case [7] the magnitude of the stresses for flange thickness of $15 \mathrm{~mm}$ was above yield limit. However, the analysis results of the current study showed that there is no praying effect in the connection's flange and there is no bending in the bolts. This is due to the flange thickness which is higher than the flange thickness in the previous studies $[7,8]$ the absence of the bolt pre-tensioning force, and using UHPFRC material for constructing the connection instead of steel material. In the present paper the magnitude of the maximum stresses for flange thickness of $500 \mathrm{~mm}$ was below yield limit as shown in Fig. 29.

\section{Comparing the results}

The developed finite element model for the cyclic simulation test was calibrated with reference experimental test results conducted in the current study. The lateral load versus lateral displacement curve obtained from the experimental test and the finite element simulation were compared in Fig. 30. The ultimate loads $\left(P_{F E A}\right)$, and the displacement $\left(\delta_{F E A}\right)$ predicted from the FE simulation were compared with experimental data as illustrated in Table 6 . The simulation results were found to be in good agreement with experimental test results. The maximum percentage of difference between the experimental and the FE simulation results for the ultimate loads is $15.3 \%$ while the difference in the maximum displacement is $73.14 \%$. The ultimate loads and displacement generated from the numerical simulations are very close to those recorded from cycling experimental test. However, the behavior of the model in the experimental test in terms of deformation, cracks and crushes were close to that obtained in the numerical analysis as shown in Fig. 31. 


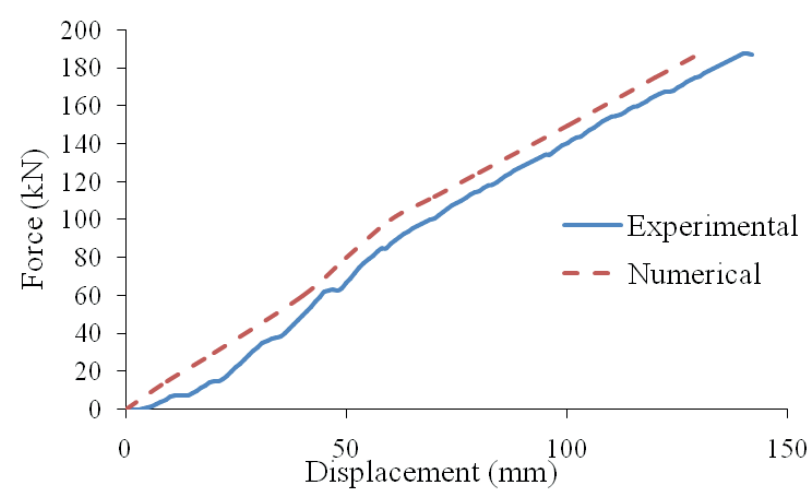

Fig. 30 The difference between the experimental results and the numerical results

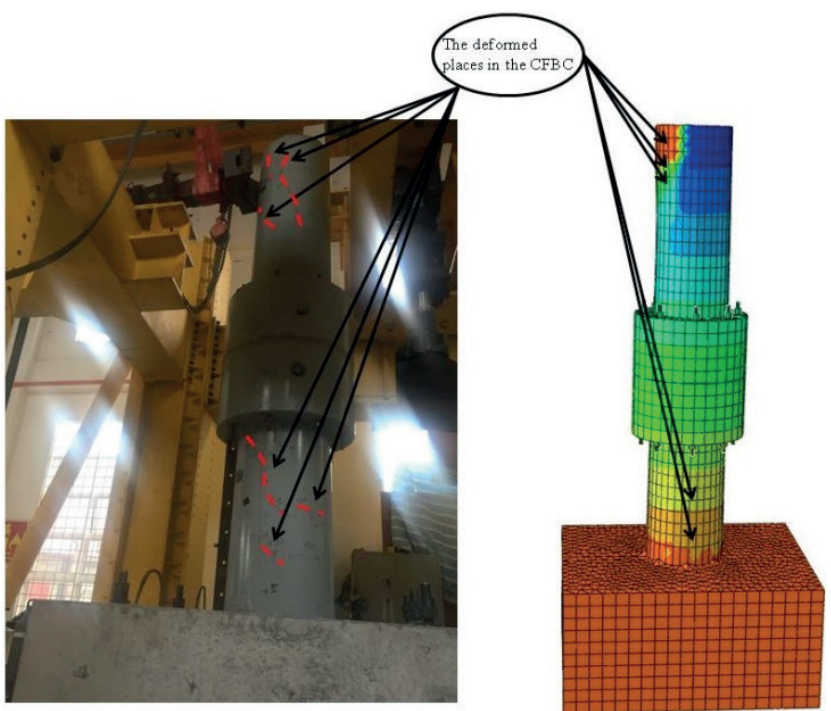

Fig. 31 The connection behavior in both experimental and numerical analysis

Table 7 Comparison between the cyclic experimental test and finite element analysis results

\begin{tabular}{lcccccc}
\hline Specimen & \multicolumn{3}{c}{ Ultimate displacement $(\mathrm{mm})$} & \multicolumn{3}{c}{ Ultimate load $(\mathrm{kN})$} \\
\hline CFBC & Exp. & FEA & Exp./FEA & Exp. & FEA & Exp./FEA \\
& 125 & 55.5 & 2.25 & 187.8 & 216.6 & 0.87 \\
\hline
\end{tabular}

Exp.: experimental result; FEA: finite element analysis result.

\section{Conclusions}

In this study, the shear and moment transfer mechanism of the circular flange bolted connection (CFBC) in UHPFRC segmental communication tower under lateral cyclic loads is studied. The CFBC specimen was investigated through FE simulation in addition to dynamic experimental test. Advanced FEA of real-scale CFBC in a tower for internet usage have been carried out depending on the verification done via experiments. Similar observations were made from the results of the experimental tests and the FE model. After the application of ultimate load the connection behaved in the similar trend in terms of overall deformations and failure type and distribution of yield in both experiment tests and FE model. The UHPFRC bolted connection was compared to the steel bolted connection of tower segment. The main conclusions drawn are as follows:

- The circular flange bolted connection (CFBC) has proven to be an effective method of connection for hollow tower segments.

- Even though some fine cracks appeared on the CFBC joint and the tower segment, the CFBC stayed stable while the cracks did not affect the performance of the connection and the hollow segments in resisting the applied load.

- Based on the comparison with previous studies, under tension, the stiffness increases with an increase in flange thicknesses while minimizing the prying effect.

- From the strain gauge results, the connection joint was observed to be the most rigid section in the circular hollow tower.

- According to the numerical and experimental results, the ultra high performance fiber reinforced concrete CFBC with epoxy resin and the hollow tower segments was observed to perform in a composite manner in resisting the lateral cyclic load. The overall lateral resistance resulted from the combination of the resistance due to UHPFRC and CFBC.

- Based on the results of experimental and numerical analysis, the model showed very high resistance against applied loads, especially in the flanges around the connection area. This could be attributed to the design of the connection and its components as well as the high strength of the UHPFRC material.

- The concrete strength has strongly dependent on load capacity, longitudinal shear transfer mechanism as well as the and the failure pattern of the CFBC system.

- No prying effect was observed in the proposed CFBC designed using UHPFRC material.

\section{Acknowledgement}

This research receives support from Dura Technology Sdn. Bhd., under a research project from Ministry of Science Technology \& Innovation, Malaysia, entitled "Development and construction of Internet Transmission Tower Using Ultra High Performance Concrete". Also, this research work, further supported by University Putra Malaysia under Putra Grant No. 9531200. Their help and support are gratefully acknowledged. 


\section{References}

[1] Heinisuo, M., Perttola, H., Ronni, H. "A step towards the 3D component method for modelling beam-to-column joints", Steel Construction, 7(1), pp. 8-13, 2014. https://doi.org/10.1002/stco.201350001

[2] Kim, J., Ghaboussi, J., Elnashai, A. S. "Hysteretic mechanical-informational modeling of bolted steel frame connections", Engineering Structures, 45, pp. 1-11, 2012.

https://doi.org/10.1016/j.engstruct.2012.06.014

[3] Prinz, G. S., Nussbaumer, A., Borges, L., Khadka, S. "Experimental testing and simulation of bolted beam-column connections having thick extended endplates and multiple bolts per row", Engineering Structures, 59, pp. 434-447, 2014. https://doi.org/10.1016/j.engstruct.2013.10.042

[4] Málaga-Chuquitaype, C., Elghazouli, A. Y. "Behaviour of combined channel/angle connections to tubular columns under monotonic and cyclic loading", Engineering Structures, 32(6), pp. 1600$1616,2010$. https://doi.org/10.1016/j.engstruct.2010.02.008

[5] Katula, L., Márai, P. "Study the prying effect on bolted base-plate connections", Periodica Polytechnica Civil Engineering, 57(2), pp. 157-172, 2013.

https://doi.org/10.3311/PPci.7171

[6] Schwingshackl, C. W., Di Maio, D., Sever, I., Green, J. S. "Modeling and Validation of the Nonlinear Dynamic Behavior of Bolted Flange Joints", Journal of Engineering for Gas Turbines and Power, 135(12), Article ID: 122504, 2013.

https://doi.org/10.1115/1.4025076

[7] Blachowski, B., Gutkowski, W. "Effect of damaged circular flange-bolted connections on behaviour of tall towers, modelled by multilevel substructuring", Engineering Structures, 111, pp. 93-103, 2016.

https://doi.org/10.1016/j.engstruct.2015.12.018

[8] Cao, J. J., Bell, A. J. "Determination of bolt forces in a circular flange joint under tension force", International Journal of Pressure Vessels and Piping, 68(1), pp. 63-71, 1996. https://doi.org/10.1016/0308-0161(95)00040-2

[9] Schaumann, P., Seidel, M. "Failure analysis of bolted steel flanges", In: Proceedings of the 7th International Symposium on Structural Failure and Plasticity (IMPLAST 2000), Melbourne, Australia, 2000, pp. 507-520. [online] Available at: https://www.stahlbau. uni-hannover.de/uploads/tx_tkpublikationen/2000_Seidel2.pdf [Accessed: 5 June 2018]

[10] Schaumann, P., Kleineidam, P. "Global Structural Behaviour of Ring Flange Joints", presented at NAFEMS Seminar: Modelling of Assemblies and Joints for FE Analyses, Wiesbaden, Germany, April, 24-25, 2002. [online] Available at: https://www.stahlbau.uni-hannover.de/uploads/tx_tkpublikationen/2002-04-24_ Kleineidam.pdf [Accessed: 5 June 2018]

[11] Pavlović, M., Heistermann, C., Veljković, M., Pak, D., Feldmann, M., Rebelo, C., da Silva, L. S. "Friction connection vs. ring flange connection in steel towers for wind converters", Engineering Structures, 98, pp. 151-162, 2015. https://doi.org/10.1016/j.engstruct.2015.04.026
[12] Abidelah, A., Bouchaïr, A., Kerdal, D. E. "Influence of the flexural rigidity of the bolt on the behavior of the T-stub steel connection", Engineering Structures, 81, pp. 181-194, 2014.

https://doi.org/10.1016/j.engstruct.2014.09.041

[13] Gutkowski, W., Blachowski, B. "Revised assumptions for monitoring and control of 3D lattice structures", presented at 11th PanAmerican Congress of Applied Mechanics (PACAM XI), Foz do Iguaçu, PR, Brazil, Jan. 4-8, 2010. [online] Available at: https:// www.researchgate.net/profile/Bartlomiej_Blachowski/publication/262535412_Revised_assumptions_for_monitoring_and_control_of_3D_lattice_structures/links/0f317537f27f400255000000/ Revised-assumptions-for-monitoring-and-control-of-3D-latticestructures.pdf [Accessed: 5 June 2018]

[14] Świercz, A., Kołakowski, P., Holnicki-Szulc, J., Olkowicz, D. "Identification of semi-rigid joints in frame structures", presented at 6th ECCOMAS Conference on Smart Structures and Materials, SMART 2013, Torino, Italy, June, 24-26, 2013. [online] Available at: http://smart.ippt.gov.pl/dok/referaty/2014_Basu_ SCHM.pdf [Accessed: 5 June 2018]

[15] Blachowski, B., Swiercz, A., Pnevmatikos, N. "Experimental verification of damage location techniques for frame structures assembled using bolted connections", presented at COMPDYN 2015, 5th ECCOMAS Thematic Conference on Computational Methods in Structural Dynamics and Earthquake Engineering, Crete Island, May, Greece, 25-27, 2015. [online] Available at: https://www.researchgate.net/profile/Bartlomiej_Blachowski/publication/277307736_ Experimental_verification_of_damage_location_techniques_ for_frame_structures_assembled_using_bolted_connections/ links/5566cb0108aefcb861d1a151.pdf [Accessed: 5 June 2018]

[16] Bogacz, R., Czyczuła, W., Konowrocki, R. "Influence of Sleepers Shape and Configuration on Track-Train Dynamics", Shock and Vibration, Article ID: 393867, 2014. https://doi.org/10.1155/2014/393867

[17] Stocki, R., Tauzowski, P., Knabel, J. "Reliability analysis of a crashed thin-walled s-rail accounting for random spot weld failures", International Journal of Crashworthiness, 13(6), pp. 693-706, 2008. https://doi.org/10.1080/13588260802055213

[18] Van-Long, H., Jean-Pierre, J., Jean-François, D. "Behaviour of bolted flange joints in tubular structures under monotonic, repeated and fatigue loadings I: Experimental tests", Journal of Constructional Steel Research, 85, pp. 1-11, 2013. https://doi.org/10.1016/j.jcsr.2013.02.011

[19] Luan, Y., Guan, Z.-Q., Cheng, G.-D., Liu, S. "A simplified nonlinear dynamic model for the analysis of pipe structures with bolted flange joints", Journal of Sound and Vibration, 331(2), pp. 325-344, 2012. https://doi.org/10.1016/j.jsv.2011.09.002

[20] Couchaux, M., Ryan, I., Hjiaj, M. "Stress concentration factors for the fatigue design of tubular flange connections", In: 11th Nordic Steel Construction Conference, Malmö, Sweden, 2009, pp. 255262. [online] Available at: http://nordicsteel2009.se/pdf/79.pdf [Accessed: 02 August 2019]

[21] Yang, J. N., Xia, Y., Loh, C.-H. "Damage Identification of Bolt Connections in a Steel Frame", Journal of Structural Engineering, 140(3), Article ID: 04013064, 2013. https://doi.org/10.1061/(ASCE)ST.1943-541X.0000831 
[22] Pnevmatikos, N. G. "Damage Detection of Structures Using Discrete Wavelet Transform", presented at 5th World Conference on Structural Control and Monitoring, Tokyo, Japan, July, 12-14, 2010. [online] Available at: http://www.bridge.t.u-tokyo.ac.jp/ WCSCM5/ [Accessed: 02 August 2019]

[23] He, J., Liu, Y., Chen, A., Wang, D., Yoda, T. "Bending behavior of concrete-encased composite I-girder with corrugated steel web", Thin-Walled Structures, 74, pp. 70-84, 2014. https://doi.org/10.1016/j.tws.2013.08.003

[24] Perttola, H., Heinisuo, M. "Experimental study on flanged joints of tubular members under biaxial bending", In: 7th International Workshop on Connections in Steel Structures, Timisoara, Romania, 2013, pp. 303-318.

[25] Henson, G., Hornish, B. "An Evaluation of Common Analysis Methods for Bolted Joints in Launch Vehicles", presented at 51st AIAA/ASME/ASCE/AHS/ASC Structures, Structural Dynamics, and Materials Conference, Orlando, FL, USA, April, 12-15, 2010. [online] Available at: https://arc.aiaa.org/doi/abs/10.2514/6.20103022 [Accessed: 02 August 2019]

[26] Pitrakkos, T., Tizani, W. "Experimental behaviour of a novel anchored blind-bolt in tension", Engineering Structures, 49, pp. 905-919, 2013.

https://doi.org/10.1016/j.engstruct.2012.12.023

[27] An, Y., Błachowski, B., Ou, J. "A degree of dispersion-based damage localization method", Structural Control and Health Monitoring, 23(1), pp. 176-192, 2016.

https://doi.org/10.1002/stc. 1760
[28] CEN " EN 1993-3-1 Eurocode 3 - Design of steel structures - Part 3-1: Towers, masts and chimneys - Towers and masts", European Committee For Standardization, Brussels, Belgium, 2009.

[29] CEN " ENV 1993-3-2:1997 Eurocode 3 - Design of steel structures - Part 3-2: Towers, masts and chimneys - Chimneys", European Committee For Standardization, Brussels, Belgium, 2006.

[30] DSM "MS 1553:2002 Code of Practice on Wind Loading for Building Structure", Department of Standards Malaysia, Putrajaya, Malaysia, 2007.

[31] Paz, M., Leigh, W. "International Building Code IBC-2000", In: Structural Dynamics, Theory and Computation, Springer, Boston, MA, USA, 2004, pp. 757-781. https://doi.org/10.1007/978-1-4615-0481-8_25

[32] ATC "Seismic evaluation and retrofit of concrete buildings, Volume 1", Applied Technology Council, Redwood City, CA, USA, Rep. SSC 96-01, 1996.

[33] Niwa, J. (ed.) "Recommendations for design and construction of Ultra High Strength Fiber Reinforced Concrete Structures (Draft)", 1st ed., Japan Society of Civil Engineers (JSCE), Tokyo, Japan, 2006.

[34] Lim, B., Matsumoto, T. "Characteristics of Super High Damping Visco-Elastic Damper for Earthquake and WindInduced Vibration", presented at 4th International Conference on Earthquake Engineering, Taipeh, Taiwan, Oct. 12-13, 2006. [online] Available at: https://conf.ncree.org.tw/Proceedings/ i0951012/data/pdf/4ICEE-0305.pdf [Accessed: 02 August 2019] 